\title{
INTERVENÇÃO BREVE GRUPAL PARA REDUÇÃO DO PADRÃO DE USO DE ÁLCOOL EM HOMENS: ENSAIO CLÍNICO RANDOMIZADO
}

\begin{abstract}
Versão restrita da tese apresentada ao Programa de PósGraduação em Enfermagem da Escola de Enfermagem da Universidade de São Paulo para obtenção do título de Doutora em Ciências.
\end{abstract}

Área de concentração: Cuidado em Saúde/Enfermagem Psiquiátrica

Orientador: Prof. Dr. Divane de Vargas

\section{VERSÃO RESTRITA CORRIGIDA}

A versão original encontra-se disponível na Biblioteca da Escola de Enfermagem da Universidade de São Paulo e na Biblioteca Digital de Teses e Dissertações da Universidade de São Paulo.

São Paulo 
AUTORIZO A REPRODUÇÃO E DIVULGAÇÃO TOTAL OU PARCIAL DESTE TRABALHO, POR QUALQUER MEIO CONVENCIONAL OU ELETRÔNICO, PARA FINS DE ESTUDO E PESQUISA, DESDE QUE CITADA A FONTE.

Assinatura:

Data:

O presente trabalho foi realizado com apoio da Coordenação de Aperfeiçoamento de Pessoal de Nível Superior - Brasil (CAPES) - Código de Financiamento 001.

Catalogação na Publicação (CIP)

Biblioteca "Wanda de Aguiar Horta"

Escola de Enfermagem da Universidade de São Paulo

León Ramírez, Erika Gisseth

Intervenção breve grupal para a redução do padrão de uso de álcool em homens: ensaio clínico randomizado / Erika Gisseth León Ramírez. São Paulo, 2020.

$57 \mathrm{p}$.

Tese (Doutorado) - Escola de Enfermagem da Universidade de São Paulo.

Orientador: Prof. Dr. Divane de Vargas

Área de concentração: Cuidados em Saúde/Enfermagem Psiquiátrica

1. Álcool. 2. Ensaio Clínico. 3. Atenção primária à saúde. 4. Homens. 5. Enfermagem. I. Título.

Ficha catalográfica elaborada por Fabiana Gulin Longhi Palacio (CRB-8: 7257) 
Nome: Erika Gisseth León Ramírez

Título: Intervenção breve grupal (IBG) para redução do padrão de uso de álcool em homens: ensaio clínico randomizado

Aprovado em: Data:

\section{Banca Examinadora}

Orientador: Prof. Dr. Divane de Vargas

Instituição: Escola de Enfermagem Universidade de São Paulo

Julgamento:

Assinatura:

Prof. Dr.

Instituição:

Julgamento:

Assinatura:

Prof. Dr.

Instituição:

Julgamento:

Assinatura:

Prof. Dr.

Instituição:

Julgamento:

Assinatura 
Este trabalho está dedicado aos meus pais, meu irmão e à minha querida esposa que sempre estiveram do meu lado, nos momentos bons e em outros não tão bons, me dando força, me animando. Cada um do seu jeito, mas com o mesmo objetivo, me fazer crescer e o mais importante não desistir dos meus sonhos.... Amo vocês!! 


\section{AGRADECIMENTOS}

Ao universo, e todas as forças superiores a mim nele contidas, que permitiram que eu chegasse até aqui em meio de dificuldades e momentos maravilhosos, que sem dúvida trouxeram grandes aprendizados.

Ao professor Divane de Vargas, pela orientação, por ter me acolhido, e depositado sua confiança em mim desde o primeiro momento, quando cheguei no Brasil sem falar português direito; pelos conhecimentos compartilhados além da academia, por ser meu porto seguro nos momentos mais difíceis, por esse seu sorriso e seu jeito de ser, pelo seu apoio e preocupação constante durante a elaboração desse trabalho. Minha eterna admiração e gratidão.

A Mily Moreno, minha companheira nesta caminhada, agradeço a você por estar junto, em cada crise, nas alegrias, nos momentos de dúvida. Você fez com que o caminho percorrido até a finalização desse trabalho fosse mais agradável e feliz.

Aos meus colegas, amigos e cúmplices, Janaina, Marina, Fernanda Matos, Simone, Carol Serna, Margarita, Inês, Maryke, Carlos, Perpétua, Priscila que fizeram o possível por estar junto, cada um de uma forma diferente, mas estatisticamente significativa. E porque cada um é um exemplo de inspiração, parceria, luta, e amor pelo próximo.

Aos meus colegas do Núcleo de Pesquisa e Estudos em Enfermagem em Adições (NEPEAA) pelo apoio durante a realização dessa pesquisa, especialmente a Janaina Soares, que inspirou a sua realização, a Caroline Figueira, pela amizade, sinceridade e pelas intermináveis discussões de madrugada, de forma geral por ter me acompanhado desde a minha chegada ao Brasil e a esta Escola. A minha amiga 
Talita Dutra Ponce pela força e apoio constante, pelas pequenas e grandes conquistas que vivemos juntas e a Gabriella Boska pela parceria, pelas aventuras, as largas conversas e a leveza nos momentos de angústia. Às Professoras Doutoras, Margareth Ângelo, Diná de Almeida Lopes Monteiro da Cruz e Maria Lucia Oliveira de Souza Formigoni por compartilhar da sua vasta experiência em pesquisa, pela sua disponibilidade sempre e pelas valiosas contribuições realizadas para a realização deste trabalho.

Às bibliotecárias Juliana Takahashi e Fabiana Palácio, pela disposição e pelas orientações.

As secretarias do Departamento de Enfermagem Materno Infantil e Psiquiátrica, Fernanda e Ana Clélia e aos funcionários da secretaria da Pós graduação pelo carinho e por sempre me atenderem cordialmente e de maneira tão resolutiva.

Aos enfermeiros e agentes comunitários da UBS Sé, especialmente à psicóloga Luiza e a assistente social Wilza por serem tão solicitas e pelo interesse em melhorar a qualidade do cuidado prestado à população usuária de álcool e outras drogas.

Aos homens atendidos na UBS Sé que participaram desse estudo e que fizeram possível a finalização dessa tese, agradeço o aprendizado e por terem compartilhado suas histórias de vida comigo, com toda certeza, eu posso dizer que não fui a mesma pessoa após cada encontro com os grupos.

Finalmente e não menos importantes devo agradecer aos meus filhotes Arturo e Agatha, por me acalmarem e me tirarem da rotina cada vez que eu precisava. 
León, EG. Intervenção breve grupal para redução do padrão de uso de álcool em homens: Ensaio clínico randomizado [tese]. São Paulo: Escola de Enfermagem, Universidade de São Paulo; 2020.

\section{RESUMO}

Introdução: Apesar dos esforços mundiais, para redução do uso problemático de álcool, observa-se que este uso na população masculina continua a ser um problema de saúde pública no mundo. No Brasil, a prevalência do uso nocivo de álcool em população maior de 15 anos é de 5,2 \% para mulheres, enquanto entre os homens é de 20,7\%. Nesse sentido, a aplicação da Intervenção Breve (IB) vem se configurando como uma estratégia efetiva na mudança do padrão de uso de risco e nocivo de álcool na população. Mais recentemente, em decorrência das limitações das IB individuais, no que se refere à otimização dos recursos humanos e à maior cobertura nos serviços de saúde, a Intervenção Breve Grupal (IBG) tem sido proposta como uma estratégia com potencial para enfrentar essas limitações. Objetivo: Avaliar a efetividade da IBG na redução do padrão de uso e no aumento da prontidão para mudança de comportamento em homens com uso de risco e nocivo de álcool atendidos na atenção primária à saúde. Metodologia: Ensaio clínico randomizado, com seguimento de 30 e 90 dias, conduzido em uma unidade de atenção primária à saúde, na região central de São Paulo (Brasil) de abril de 2018 a dezembro de 2019. Foram randomizados 112 homens, dos quais 55 foram alocados no grupo experimental e 57 no grupo controle. Os desfechos padrão de uso e prontidão para mudança foram avaliados em ambos os grupos, utilizando o Alcohol Use Disorders Identification Test (AUDIT) e a régua de prontidão para mudança (RPM). O grupo experimental recebeu uma sessão de intervenção breve grupal tendo como ingrediente ativo o modelo FRAMES, enquanto o grupo controle foi orientado a continuar com o atendimento padrão da unidade. Os dados foram analisados por intenção de tratar, utilizando o método GEE (Generalized Equations Estimating). Conclusões: Os resultados deste estudo sugerem que homens com uso de risco ou nocivo de álcool atendidos em serviços de APS podem se beneficiar da aplicação da IBG, a qual se apresentou como uma abordagem efetiva e com potencial na redução do uso de álcool e no aumento da prontidão para mudança de comportamento nesta população.

Palavras chave: Intervenção breve, Grupo, Álcool, Atenção primária à saúde, Enfermagem. 
Leon, EG. Brief group intervention to reduce the alcohol use in men: Randomized clinical trial [thesis].

São Paulo: School of Nursing, University of São Paulo; 2020.

\begin{abstract}
Introduction: Despite worldwide efforts to reduce the problematic alcohol use, it is observed that this use in the male population continues to be a public health problem in the world. In Brazil, the prevalence of harmful alcohol use in a population over 15 years old is $5.2 \%$ for women, while among men it is $20.7 \%$. In this sense, the application of Brief Intervention (BI) has been configured as an effective strategy in changing the risk and harmful alcohol use in the population. More recently, due to the limitations of individual IB, regarding the optimization of human resources and greater coverage in health services, the Brief Group Intervention (BGI) has been proposed as a strategy with the potential to face these limitations. Objective: To evaluate the effectiveness of the IBG in reducing the alcohol use and increasing the readiness for behavior change in men with risk and harmful alcohol use treated in primary health care. Methodology: Randomized clinical trial, with a follow-up of 30 and 90 days, conducted in a primary health care unit, in the central region of São Paulo (Brazil) from April 2018 to December 2019. Were randomized 112 men, of which 55 were allocated to the experimental group and 57 to the control group. The alcohol use and the readiness for change were assessed in both groups, using the Alcohol Use Disorders Identification Test (AUDIT) and the Readiness for Change (RTC) rule. The experimental group received a brief group intervention session with the FRAMES model as an active ingredient, while the control group was instructed to continue with the usual care of the unit. The data were analyzed by intention to treat, using the GEE method (Generalized Equations Estimating. Conclusions: The results of this study suggest that men with risky or harmful alcohol use seen in PHC services may benefit from the application of IBG, which has been shown to be an effective approach with the potential to reduce alcohol use and increase readiness to change behavior in this population.
\end{abstract}

Keywords: Brief intervention, Group, Alcohol, Primary health care, Nursing. 


\section{LISTA DE SIGLAS}

APS

AUDIT

ECR

EEUSP

FRAMES

GC

GE

IB

IBG

IBI

LGBT

NEPEAA

OMS

OPAS

RPM

SBIRT

SENAD

UBS

WHO
Atenção primária à saúde

Alcohol use disorders test.

Ensaio clínico randomizado

Escola de Enfermagem da Universidade de São Paulo

Feedback, Responsability, Advice, Menu of options, Self-efficacy

Grupo controle

Grupo experimental

Intervenção Breve

Intervenção Breve Grupal

Intervenção Breve Individual

Lesbicas, Gays, Bissexuais e Transexuais

Núcleo de estudos e pesquisas em Enfermagem em adições

Organização Mundial da Saúde

Organização Pan-americana da Saúde

Régua de prontidão para mudança

Screening, Brief intervention, e Referral to treatment

Secretaria Nacional de Políticas sobre Drogas

Unidade básica de saúde

World Health Organization 


\section{SUMARIO}

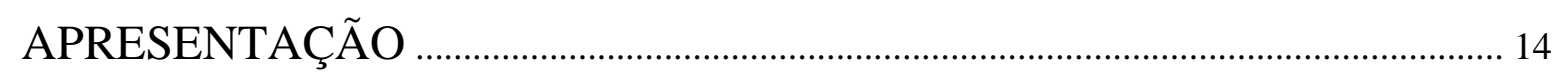

\section{CAPÍTULO I}

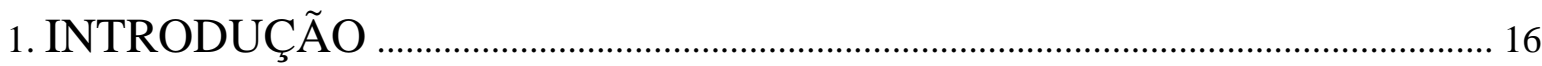

1.1 Intervenção breve (IB) ............................................................................................. 18

\section{CAPÍTULO II}

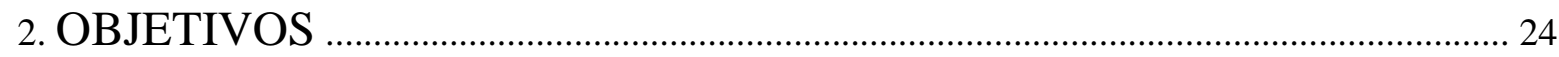

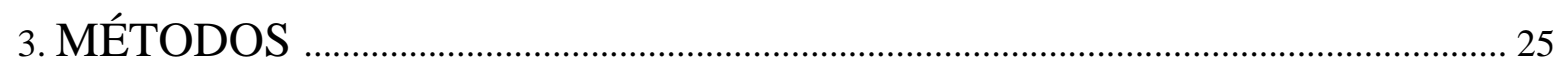

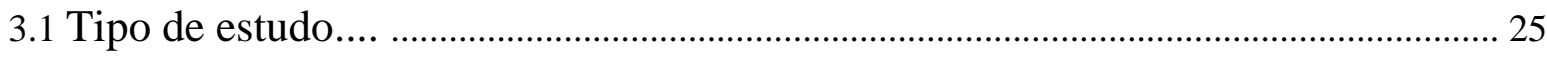

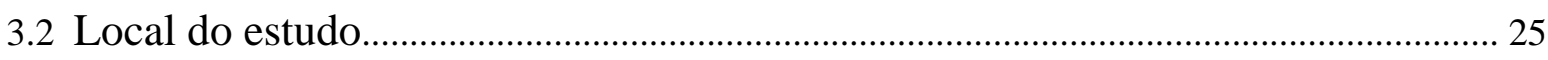

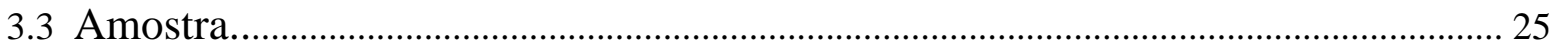

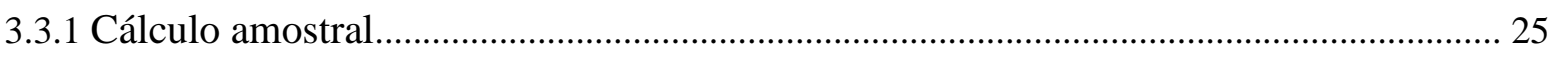

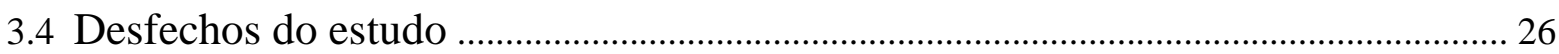

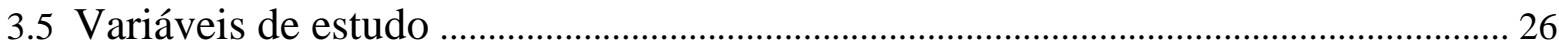

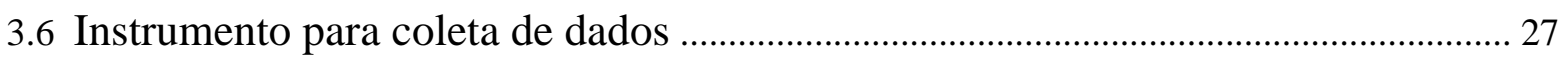

3.7 Procedimentos do estudo …………………………………………………………….. 27

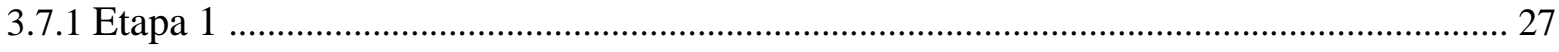

3.7.2 Etapa 2 - Treinamento..................................................................................... 27

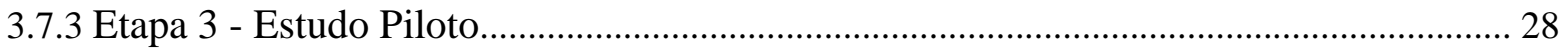

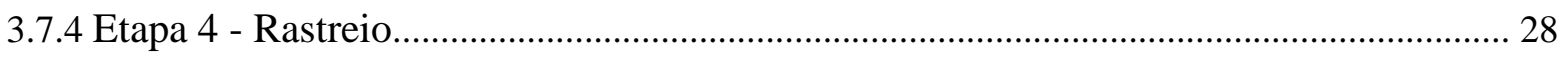

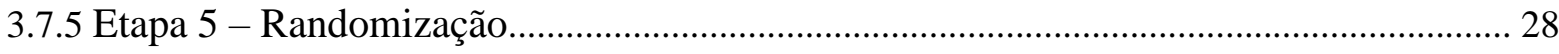

3.7.6 Etapa 6 - Grupo experimental e Grupo Controle........................................................... 29

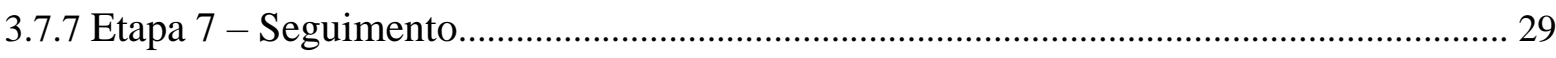

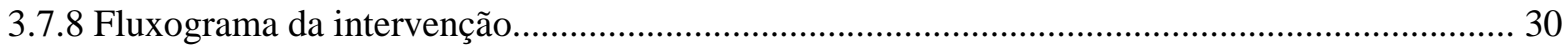

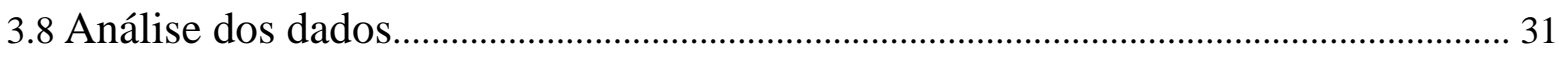

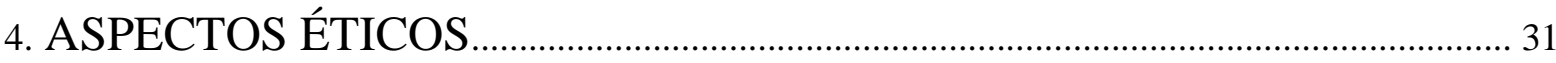




\section{CAPÍTULO V}

7. CONCLUSÕES

8. IMPLICAÇÕES PARA PRÁTICA ……………………………………………….... 90

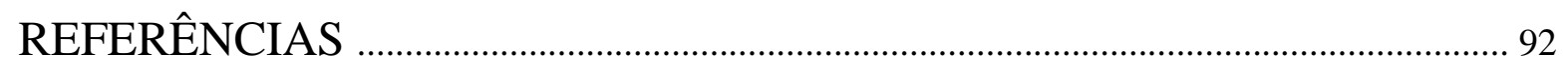

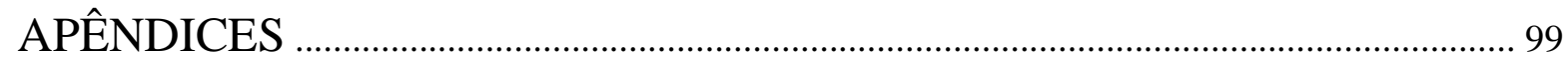

Apêndice A - Questionário sociodemográfico........................................................................ 100

Apêndice B - Termo de consentimento livre e esclarecido................................................. 102

Apêndice C - Formulário de agendamento ............................................................................ 104

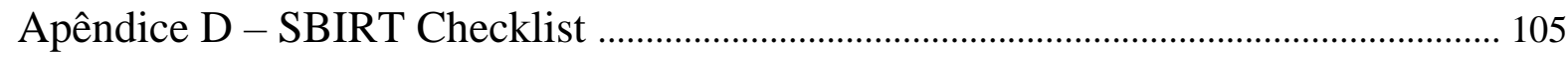

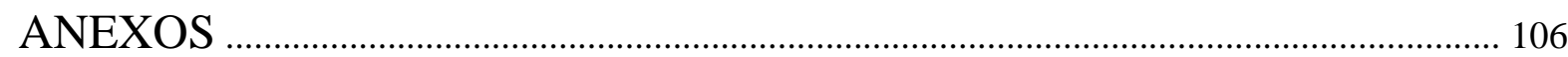

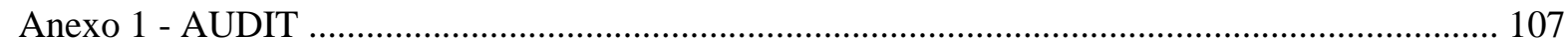

Anexo 2- Aprovação comitê de ética em pesquisa EEUSP.............................................................. 108

Anexo 3- Aprovação comitê de ética Secretaria Municipal da Saúde SP......................................... 110

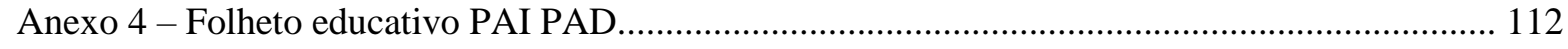

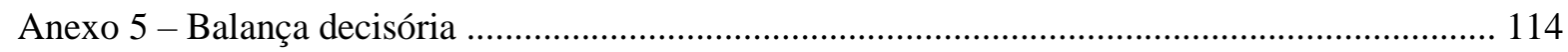




\begin{abstract}
APRESENTAÇÃO
Esta tese está estruturada em cinco capítulos, contendo uma coletânea de artigos que serão mantidos em acervo reservado na Biblioteca Digital de Teses e Dissertações da USP pelo período de dois anos. Assim, serão apresentados apenas os seguintes capítulos:

O primeiro capítulo, que inclui a introdução ao problema de pesquisa, o capítulo seguinte com os objetivos e o percurso metodológico utilizado para o desenvolvimento do estudo de forma geral e alguns detalhes do método utilizado em cada artigo que será apresentado posteriormente. O quinto e último capítulo apresenta as conclusões, as implicações desta pesquisa para prática, as referências, os apêndices e os anexos.
\end{abstract}


CAPÍTULO I 


\section{INTRODUÇÃO}

Os usuários de álcool representam mais da metade da população mundial (57\%) (World Health Organization, 2018). Historicamente, o álcool tem sido considerado como uma substância que permeia diversas esferas sociais, incorporando-se às diversas culturas que existem no mundo, por meio de rituais, festas, comemorações, tornando-o uma das substâncias psicoativas mais consumida no mundo (Nelson, 2016).

Estima-se que $28,7 \%$ das mortes no mundo estão relacionadas direta ou indiretamente com o uso nocivo de álcool, com diferenças relevantes entre homens e mulheres, sendo 237 milhões e 46 milhões, respectivamente (World Health Organization, 2018). Nos Estados Unidos, cerca de $13,7 \%$ da população apresenta algum transtorno relacionado ao uso nocivo de álcool. Desses, 7,7\% já procuraram ajuda ou tratamento, sendo que grande parte dessa porcentagem é representada por homens (Nolen-Hoeksema, 2004).

A região das Américas e a região europeia são definidas, pela Organização Mundial da Saúde, como as áreas de maior prevalência de transtornos relacionados ao uso de álcool entre homens e mulheres no mundo, sendo: região europeia, $14,8 \%$ e 3,5\%, e região das Américas, 11,5\% e 5,1\%, respectivamente (World Health Organization, 2018). Entre 2013 e 2015, o uso nocivo de álcool nas Américas aumentou de 4,6\% a 13\%, nas mulheres, e de 17,9\% a 29,4\%, nos homens. No Chile, as mulheres apresentam porcentagens de uso nocivo muito baixas $(0,1 \%)$, enquanto a população masculina apresenta frequência desse uso de 13,5\%. No Brasil, também tem se apontado diferenças do uso nocivo de álcool entre gêneros, com aumento de $38 \%$ a 47\%, em homens, e de 17\% a $27 \%$, em mulheres, entre 2006 e 2012 (INPAD, 2013). Além disso, estudo salienta que, nos últimos 10 anos houve aumento de 3,4 \% em relação ao uso nocivo da bebida alcoólica na população geral do país (Ministério da Saúde do Brasil, 2017). Tais dados indicam a necessidade de oferecer maior cuidado à população que faz uso nocivo do álcool e prestar atenção às particularidades de gênero, pois observa-se, de forma geral, que apesar da quantidade de mulheres que fazem uso nocivo de álcool, ainda há porcentagem maior de homens exposta às consequências desse uso.

O uso problemático de álcool na população masculina e as alterações decorrentes desse uso têm sido evidenciados no cenário mundial. Estudo realizado em Oregon (Capaldi et al., 2015) apontou que a maioria dos homens entrevistados fazia uso de altas quantidades de bebida alcoólica e que, especificamente aqueles na faixa etária de 35 a 36 anos (13,3\%), evidenciaram em algum momento problemas crônicos relacionados a esse uso. Na Europa, o uso de álcool entre homens encontra-se relacionado fortemente à masculinidade como conceito social, a qual 
desempenha papel fundamental nos padrões de uso de álcool em homens, pois esse padrão está influenciado pelo estereótipo do papel masculino na sociedade, fazendo com que o uso de álcool se torne um instrumento de medida para outros domínios da identidade do homem; ou seja, quem mais bebe, é considerado mais homem entre seus pares (De Visser \& Smith 2007).

Estudo realizado na Suíça (Studer et al., 2014) apontou que 49,9\% dos homens apresentavam pelo menos uma situação de risco relacionada à bebida ou faziam uso nocivo dessa substância, além de pontuar que a pressão realizada por outros homens e a busca de métodos de afrontamento a situações de estresse tornam-se os motivos mais persistentes associados ao uso abusivo da bebida (Studer et al., 2014). Dentre outros fatores associados a esse padrão de uso, encontrou-se uma tendência da população masculina a desenvolver comportamentos impulsivos que colocam em risco sua saúde.

Em outros continentes, não é diferente: na África do Sul, o consumo abusivo de álcool entre homens é o maior problema psicossocial que o país enfrenta (Gossage et al., 2014), pois esse consumo é considerado como um ícone da perpetuação da hegemonia masculina no decorrer da história, sempre atrelado à socialização entre pares do mesmo sexo (Lesch, 2017). No que diz respeito à América Latina, a masculinidade também aparece como um constructo ligado ao consumo abusivo do álcool. A Organização Pan-Americana da Saúde (Organización Panamericana de la Salud, 2016) indica que o número de homens que fazem uso nocivo dessa substância tem aumentado nos últimos anos, passando de $18 \%$ para 30 \%, entre 2010 e 2015 . Além disso, $6 \%$ da população desta região já apresentaram algum transtorno relacionado com o seu uso.

No Brasil, a prevalência do uso nocivo é de $20,7 \%$, para homens em relação à população geral, desses, $28,8 \%$ desenvolveram doenças graves como cirrose hepática. Cerca de $12 \%$ dessa população precisam de atendimento eventual de saúde mental, tornando-se necessário pensar em "problemas associados ao uso nocivo de álcool" além de apenas se pensar na "dependência", devido às tendências de consumo encontradas, que podem levar a sérios danos à saúde e a outras esferas do contexto dos indivíduos (World Health Organization, 2014).

Aliado a isso, sabe-se das dificuldades presentes, no território brasileiro, com relação à baixa procura dos serviços de atenção primária à saúde, porque evidencia-se que os homens possuem dificuldade ainda maior, pois possuem taxa de concentração de consultas/ano 71 vezes menor $(0,06)$ do que as mulheres (4,3) (Ministério de saúde do Brasil, 2012). Uma provável explicação para essa diferença é relatada em um estudo realizado com profissionais em diversas unidades de atenção primária à saúde, o qual aponta que historicamente esses serviços têm sido desenhados para priorizar os cuidados à mulher e à criança, o que pode ter influenciado a baixa 
participação dos homens nesses espaços de cuidado, fragilizando ainda mais a criação do vínculo com os profissionais do serviço (Gomes et al., 2011).

A partir da política nacional de atenção integral à saúde do homem (Ministério da saúde do Brasil, 2008), pretendeu-se garantir o acesso dessa população aos serviços de saúde; entretanto, esta acessibilidade mostra-se prejudicada, já que essa população apresenta procura bastante reduzida dos serviços de atenção primária à saúde (Brito et al., 2010). Esse fenômeno pode se associar aos diferentes modelos de masculinidade, que não reconhecem o autocuidado como prática, o que acaba revertendo no afastamento do usuário (Gomes et al., 2011; Peres et al., 2015). Existem também dificuldades derivadas do sistema de saúde, como falta de recursos físicos e de infraestrutura das unidades, pobre mobilização da população, estigma e resistência dos profissionais, pouca participação e envolvimento dos gestores e horários de funcionamento que competem com o horário de trabalho o que acaba contribuindo à baixa adesão e à baixa procura da população masculina.

No que diz respeito às intervenções para redução do uso nocivo de álcool na atenção básica, não é diferente, pois trata-se de uma condição presente na população masculina, que deve ser atendida neste cenário de cuidado. Entretanto, apesar dos esforços mundiais em promover estratégias para redução desse uso na população, observa-se que o uso problemático de álcool continua a ser um problema de saúde pública, especificamente na América Latina, por ser uma das regiões que mais apresenta uso nocivo da substância, atingindo majoritariamente a população masculina (Organização Pan-Americana da Saúde, 2015).

Diversas estratégias têm sido utilizadas para atender as necessidades das pessoas que fazem uso nocivo de álcool no âmbito da atenção primaria à saúde; no entanto, ainda apresentam limitações importantes (Costa et al., 2013b). Dentre as estratégias mais utilizadas no mundo, para redução do uso nocivo de álcool na atenção primária à saúde, encontra-se a intervenção breve (IB) (Babor et al., 2007). A IB tem sido definida, pela Substance Abuse and Mental Health Services Administration (SAMHSA), como uma abordagem de saúde pública globalizada cujo foco é identificar precocemente as pessoas que fazem uso de risco e nocivo de álcool, prevenir e encaminhar oportunamente aquelas que desenvolveram algum transtorno relacionado com o uso nocivo dessa substância (Babor et al., 2007; Strobbe, 2014).

\subsection{Intervenção breve (IB)}

A intervenção breve trata-se de uma técnica utilizada inicialmente para tratamento de pessoas com transtornos relacionados ao uso de álcool, cujos objetivos são aumentar a motivação e auxiliar a pessoa a desenvolver habilidades para promover mudanças no 
comportamento de beber, seja reduzindo o uso ou diminuindo os danos decorrentes do mesmo (Babor et al., 2007). A Organização Mundial da Saúde sugere a aplicação da técnica da intervenção breve, utilizando uma única sessão, mostrando indicadores de efetividade com duração aproximada de 30 minutos (Bien et al., 1993; Minto et al., 2007). Com relação aos indicadores de efetividade, múltiplas revisões sistemáticas (Ballesteros et al., 2004; Babor et al., 2007; Pereira et al., 2013; Clossick, 2014; Elzerbi et al., 2015; Kaner et al., 2018) têm sustentado vasta evidência acerca do impacto da intervenção breve na redução do padrão de uso de álcool em diversas populações, dentre elas a população masculina.

O efeito da intervenção breve depende diretamente dos seus componentes e ingredientes ativos, pois são eles os responsáveis por sua efetividade na motivação dos usuários para mudança de comportamento em relação ao uso do álcool. Apesar de existirem diferentes modelos, de forma geral, utiliza-se o modelo FRAMES, para aplicação da intervenção breve. Em 1993, o acrónimo FRAMES foi apresentado por Miller e Sanchez como uma forma de sintetizar o conjunto de elementos críticos encarregados de promover mudanças nas pessoas, o acrónimo foi traduzido para o português como “ADERIR", após uma conferência realizada pelo Doutor Miller no Brasil (Miller, 2001); no entanto, a sigla utilizada continua sendo FRAMES. O significado do acrónimo contém os seguintes termos por extenso:

Feedback $(F)$ ou Devolução, trata-se de esclarecer ao usuário sua situação atual em relação ao álcool e as consequências negativas decorrentes do seu uso. Isso pode ser realizado discutindo com o usuário o resultado de testes objetivos, como o AUDIT, o CAGE ou o ASSIST (Miller, 2001).

Responsabilidade $(\mathrm{R})$, deve-se trabalhar para responsabilizar o usuário sobre seu cuidado, ou seja, ele deve compreender que é o único que pode aceitar e participar das ações de saúde a serem tomadas.

Aconselhamento (A), trata-se de estabelecer uma relação na qual o profissional de saúde possa ajudar e orientar o indivíduo na compreensão das dificuldades que ele está enfrentando naquele momento.

Menu de opções $(\mathrm{M}),-$ o usuário deve escolher a melhor opção que se adeque a suas necessidades, a partir de uma gama de possibilidades construída conjuntamente com o terapeuta.

Empatia $(E)$, é um aspecto importante na comunicação e nas interações humanas (Melchers et al., 2016), que influencia determinantemente a prontidão para mudança de comportamentos. 
Self-efficacy (S) ou Autoeficácia, seu objetivo é conseguir que o usuário acredite em que ele mesmo tem a capacidade de mudar (Miller, 2001).

Em relação a sua efetividade, pesquisas têm sido realizadas em diversos contextos, populações e regiões no mundo todo. Os primeiros estudos sobre a efetividade da intervenção breve (Chafetz,1962) foram realizados com pacientes diagnosticados com alcoolismo em unidades hospitalares, cujos resultados apontaram a intervenção breve como um facilitador, para encaminhar os pacientes a serviços especializados, e como um fator relacionado a maiores taxas de adesão ao tratamento quando comparada com outros tipos de abordagem de cunho confrontador (Chafetz et al., 1962).

Apesar de ser muito aplicada na década de 1970, a intervenção breve passou a ser reconhecida e detalhadamente descrita somente em 1989 (Sanchez, 1989), com uma publicação ampliada sobre seus componentes e formas de aplicação. Posteriormente, conforme revisão sistemática de literatura (Bien et al., 1993), que avaliou 32 ensaios clínicos com aproximadamente 6.000 participantes, a intervenção breve mostrou-se como uma estratégia consolidada, útil e efetiva na atenção a indivíduos que fazem uso nocivo de álcool, ressaltando sua influência direta no seu comportamento ainda no âmbito hospitalar, incluindo serviços de emergência e diversos ambulatórios (Bien et al., 1993).

Os resultados publicados até esse momento servem como alavanca para que a OMS promova um dos maiores ensaios clínicos em nível mundial, aplicado em dez países e em duas fases: a validação de testes de identificação precoce do uso problemático de álcool; e a avaliação da efetividade da intervenção breve no âmbito da atenção primária à saúde (Saunders et al., 1993a, 1993b; McCambridge, 2014). Os resultados da aplicação da intervenção breve em indivíduos que faziam uso de risco e nocivo de álcool foram positivos, indicando maior efetividade na população masculina. Tais achados têm promovido a realização de múltiplos estudos sobre a aplicação da intervenção breve.

Estudo realizado nos Estados Unidos, no qual participaram 459.599 indivíduos, dos quais $22,7 \%$ indicaram uso nocivo de álcool, apontou que a utilização combinada dos instrumentos de identificação precoce e da intervenção breve foi efetiva, indicando diminuição de 38,7\% do uso de álcool em até 6 meses após a intervenção (Madras et al., 2009). Outro estudo, realizado nos Emirates Árabes, corroborou a efetividade da IB quando aplicada a 21 indivíduos com uso de risco e nocivo de álcool, indicando que aqueles participantes que tiveram melhores resultados eram do sexo masculino (Matheson et al., 2017). A aplicação da IB em homens com uso de risco e nocivo de álcool tem sido documentada como uma prática altamente efetiva no contexto da atenção primária à saúde em âmbito internacional (Babor, 2000; Lock et 
al., 2006). Conforme revisão realizada por Pereira (2013), na maioria de estudos que incluíram a intervenção breve, os homens representavam grande porcentagem que se beneficiou desta no contexto da atenção primária à saúde (Pereira et al., 2013).

No que diz respeito ao território brasileiro, existem estudos (Ronzani et al., 2005, 2007; Humeniuk et al., 2012; Soares, 2019) que têm visado avaliar a efetividade do uso da IB na atenção primaria à saúde, os quais apontam que a aplicação da intervenção breve é promissória na redução do uso de álcool em indivíduos que fazem uso de risco e nocivo dessa substância, especialmente na população masculina. No entanto, os autores apontam algumas dificuldades na implantação dessa estratégia, que não são alheias àquelas encontradas no contexto latinoamericano (Ronzani et al., 2005, 2007; Costa et al., 2013). Dentre as dificuldades citadas, as limitações de infraestrutura e recurso humano são as mais destacadas, seguidas de aspectos ligados ao próprio sistema de saúde, à falta de engajamento e à descrença dos profissionais de saúde neste tipo de abordagens (Ronzani et al., 2005).

Contudo, diversos autores (Flórez, 2009; Soares 2016; Bernstein et al., 2017) têm se preocupado com a elaboração de propostas alternativas que auxiliem no processo de implementação da intervenção breve, apontando a utilização de estratégias grupais com o intuito de usufruir as vantagens dessa modalidade na redução do padrão de uso de álcool nesta população. A aplicação da intervenção breve em formato de grupo pode ser uma estratégia potencial na mudança do padrão de uso de risco e nocivo no âmbito da atenção primária à saúde e no âmbito comunitário, além de ter se mostrado útil no aumento da prontidão para mudança de comportamento. Tais fatos são sustentados por um estudo piloto realizado nos Estados Unidos (Van Horn, 2001), que utilizou a intervenção breve em formato grupal, por meio da técnica da entrevista motivacional, aplicada a 304 pacientes de um hospital psiquiátrico, os quais possuíam algum transtorno relacionado ao uso de álcool. Os encontros foram realizados com grupos de no máximo cinco pessoas, com duração de 45 minutos. O estudo não apresenta dados quantitativos robustos; no entanto, pode-se evidenciar que a intervenção grupal foi capaz de gerar alteração nos estágios de prontidão para mudança nesta parcela de usuários.

Na América Latina, estudo colombiano de Flórez (2009) avaliou as diferenças entre formatos da intervenção breve, dentre os quais o formato grupal. As intervenções foram aplicadas a 180 estudantes universitários que apresentavam uso de risco e nocivo de álcool. Os resultados indicaram que a intervenção grupal teve maior impacto, diminuindo a frequência e a intensidade do uso quando comparada com a intervenção individual. Esses resultados se mantiveram inclusive durante o seguimento de avaliação (Flórez, 2009). Mais recentemente, no Brasil, estudo realizado no contexto da atenção primária à saúde (Soares, 2019), com 180 
indivíduos que faziam uso de risco e nocivo de álcool, mostrou que a aplicação da intervenção breve em formato de grupo foi efetiva, indicando redução estatisticamente significativa de cerca de 10 pontos no escore do AUDIT após a intervenção, mantendo os usuários em padrão de baixo risco durante o seguimento. Com relação à efetividade da intervenção, nos estágios de prontidão para mudança do padrão do uso do álcool, o estudo apresentou aumento dos escores

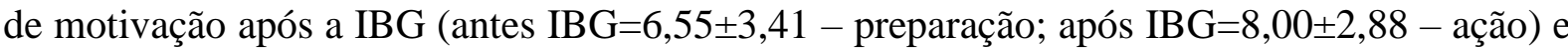

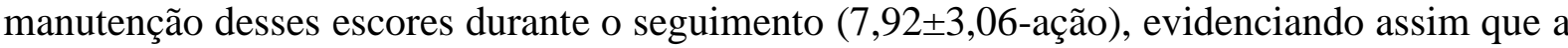
intervenção breve grupal, no contexto da APS, é uma tecnologia de cuidado efetiva para redução do consumo de álcool em indivíduos com padrão de uso de risco e nocivo, bem como influencia positivamente nos estágios de prontidão para mudança do hábito de beber nesses usuários.

Diante dos dados que a literatura apresenta, pode-se afirmar que a intervenção breve grupal pode ser considerada como uma alternativa às abordagens individuais, algumas vezes pouco exequíveis pelas características particulares dos sistemas de saúde na América Latina dentre eles o brasileiro. Evidencia-se também que há escassez de estudos sobre a aplicação desta técnica em formato grupal e aqueles existentes representam algumas das limitações a serem superadas, dentre as quais a definição do número de sessões que garantam a efetividade e a adesão das pessoas que participam da intervenção. Isto foi abordado no estudo de Soares (2016), cuja caracterização da população masculina desistente resgatou a importância de diminuir o número de sessões, com o intuito de controlar o número de desistências entre uma sessão e outra.

Além disso, destaca-se a importância da oferta, uma vez que a maioria da população não tem disponibilidade em horário laboral (Soares, 2019), sendo necessário analisar horários alternativos junto à gestão para garantir o direito dessa população ao acesso aos serviços de saúde oferecidos no âmbito da atenção primária à saúde - no qual encontra-se inserida a prevenção do uso abusivo de álcool.

Portanto, é um desafio realizar um estudo que permita resgatar a importância e demonstrar a efetividade da intervenção breve grupal na redução do padrão de uso em homens, no âmbito da atenção primária à saúde, utilizando o modelo FRAMES, com vistas a superar as limitações apontadas em estudos anteriores e garantir sua aplicação com confiabilidade e segurança no território brasileiro. 
CAPÍTULO II 


\section{OBJETIVOS}

* Realizar uma revisão sistemática da literatura sobre a utilização e a efetividade da intervenção breve grupal na redução do padrão de uso de álcool em população adulta (Artigo 1).

* Verificar a factibilidade da utilização da intervenção breve grupal na redução do padrão de uso de álcool e no aumento da prontidão para mudança em homens com uso de risco e nocivo de álcool atendidos em uma unidade de atenção primária à saúde (Artigo 2).

* Avaliar a efetividade da intervenção breve grupal na mudança do padrão de uso e da prontidão para mudança em homens com uso de risco e nocivo de álcool quando comparada ao cuidado usual recebido em uma unidade de atenção primária à saúde (Artigo 3 ). 


\section{METODOLOGIA}

\subsection{Tipo de estudo}

Trata-se de um ensaio clínico de intervenção complexa, com distribuição randômica e seguimento de 30 e 90 dias. O ensaio clínico é considerado o padrão ouro em relação a estudos que avaliam a eficácia de uma intervenção, devido ao rigor e à exigência dos seus procedimentos. Caracteriza-se por envolver pelo menos um tratamento experimental e um grupo controle e por utilizar, de preferência, um processo de aleatorização dos indivíduos do estudo (Parfrey, 2015). Esse tipo de estudo visa reduzir a probabilidade de viés nos resultados, favorecendo sua reprodutibilidade (Schulz, 2002).

\subsection{Local do estudo}

Os dados foram coletados no período de abril de 2018 a dezembro de 2019 nas instalações da unidade de atenção primária à saúde Sé, localizada no centro da cidade de São Paulo, região que, segundo a Prefeitura Municipal de São Paulo, atende aproximadamente 416.851 pessoas, distribuídas em 8 UBS - dentre essas Sé. Os usuários que frequentam esta UBS se caracterizam por serem: adultos jovens ( 20 a 39 anos $=34,3 \%$ ), seguidos de idosos $(14,5 \%)$ e $54,9 \%$ mulheres. As doenças com maior prevalência são hipertensão $(12,8 \%)$ e diabetes $(4,4 \%)$, evidenciando dependência alcoólica em 0,2\% (Datasus 2015). Apesar das particularidades presentes na região central da cidade de São Paulo, tais dados são condizentes com as características populacionais de outras unidades de atenção primária à saúde da cidade de São Paulo.

\subsection{Amostra}

O estudo foi configurado para homens usuários de álcool, que frequentavam a unidade de atenção primária à saúde e que preenchiam os seguintes critérios de inclusão: ser maior de 18 anos, saber ler e escrever e obter pontuação no AUDIT entre 8 e 19; ou seja, aqueles indivíduos classificados como usuários de risco ou nocivo de álcool. Critérios de exclusão: estar em tratamento ou frequentar algum grupo relacionado com o uso de álcool, ser portador de incapacidade cognitiva, que impeça a compreensão dos termos da pesquisa, estar intoxicado ou sob efeito de alguma substância psicoativa e aqueles que, por algum motivo de saúde, forem internados após inclusão no estudo. 


\subsubsection{Cálculo amostral}

Foi realizado um estudo piloto, com 70 indivíduos randomizados aleatoriamente, no grupo experimental (36) e no grupo controle (34). O objetivo do estudo piloto foi verificar a factibilidade da intervenção grupal no contexto descrito e fornecer subsídios para o cálculo amostral no desenvolvimento de um estudo posterior.

Para o ensaio clínico, o dimensionamento amostral foi calculado com base no tamanho do efeito identificado no estudo piloto $\left(\mathrm{d}^{2}=0,018\right)$, utilizando o Generalized liner mixed model com poder de 0,80 .

\subsection{Desfechos do estudo}

* Mudança do padrão de uso - refere-se à redução da quantidade ou da frequência do uso de álcool em participantes classificados com uso de risco ou nocivo. O padrão de uso foi classificado conforme o instrumento AUDIT (Alcohol Use Disorders Identification Test) em quatro categorias: uso de baixo risco, uso de risco, uso nocivo e provável dependência.

* Avanço nos estágios de prontidão para mudança - é avaliado mediante a RPM (régua de prontidão para mudança), com o intuito de identificar qual abordagem é mais adequada conforme o desejo de mudança.

\subsection{Variáveis do estudo}

* Variáveis dependentes: padrão de uso (frequência e quantidade) e estágio de prontidão para mudança.

* Variáveis independentes: intervenção breve grupal (grupo experimental), cuidado usual (grupo controle) e variáveis sociodemográficas.

\subsection{Instrumentos para coleta de informações no estudo}

Foram utilizados os seguintes instrumentos para coleta de dados:

O AUDIT (Alcohol Use Disorders Identification Test) (Anexo 1), elaborado nos Estados Unidos e divulgado em outras línguas (World Health Organization, 2001), é uma ferramenta com evidência robusta de validez e confiabilidade em diversos países, as quais possuem demonstrada sensibilidade (100\%) e especificidade $(76 \%)$ para identificar uso de risco e nocivo de álcool na população masculina (Méndez, 1999). Foi validado no Brasil em diversos tipos de população por diversos estudos (Lima et al., 2005; Moretti-Pires, 2011; Santos et al., 2012), sendo que só um avaliou índices de sensibilidade (76,4\%) e especificidade (75\%). É composto por 10 itens, distribuídos em dois fatores - o primeiro, encarregado de medir o 
consumo em termos de quantidade e frequência (padrão de uso), e o segundo, que avalia problemas relacionados com o uso de álcool (Lima et al., 2005; Santos et al., 2012).

A pontuação total do AUDIT oferece a classificação do padrão de uso por zonas, o que permite realizar a identificação precoce de possíveis problemas relacionados com o uso de álcool. A Zona I (até 7 pontos) é do uso de baixo risco ou abstinência; a Zona II (8 a 15 pontos) indica uso de risco; a Zona III (16 a 19 pontos) é do uso nocivo ou prejudicial; e a Zona IV (acima de 20 pontos) sugere uma provável dependência (Babor, 2000).

Para avaliação da prontidão para mudança, foi utilizada a régua de prontidão para mudança (RPM), uma escala de 0 a 10 elaborada por Rollnick (2008), cujo objetivo é avaliar a prontidão de mudança de um indivíduo frente a um comportamento específico. Posteriormente, a régua foi adaptada por Sobell (2013), o qual acrescentou pontos de corte mais específicos para facilitar a identificação do estado de prontidão: Pré-Contemplação 1-3 (PC); Contemplação 4-5 (C); Preparação 6-7 (P); Ação 8-9 (A); e Manutenção 10 (M) (Figura 1) (Sobell, 2013). Ao utilizar a régua de prontidão para mudança, deve-se perguntar ao indivíduo quão pronto ele se sente para mudar x comportamento, em uma escala de 10 pontos, onde 1 é definitivamente não está pronto e 10 definitivamente encontra-se pronto para mudar. Além de identificar o estágio de motivação de forma individual, a régua permite trabalhar em grupo aspectos diretamente relacionados com a motivação, o compartilhamento de desejos e as experiências de mudanças e interações que potencializam as intervenções realizadas.

Figura 1. Régua de prontidão para mudança (Sobell, 2013).

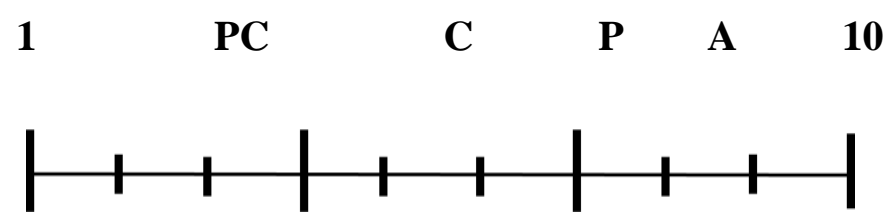

Foi aplicado, conjuntamente, um questionário (Apêndice A) de dados sociodemográficos - como sexo, idade, estado civil, raça, escolaridade e ocupação. Dados clínicos - como patologias prévias e atuais, além de tratamento farmacológico. Finalmente, dados comportamentais contendo informações sobre uso de substâncias psicoativas e realização de atividade física. 


\subsection{Procedimentos do estudo}

A presente pesquisa foi desenvolvida em sete etapas, conforme detalhadas a seguir.

\subsubsection{Etapa 1}

Imersão direta no campo de trabalho de agosto a dezembro de 2017, período no qual foram realizadas apresentações da pesquisa para as oito equipes da estratégia saúde da família (ESF), para cada grupo de categoria profissional (médicos e enfermeiras) e foram realizadas jornadas de sensibilização para toda a equipe da unidade de atenção primária à saúde.

\subsubsection{Etapa 2 - Treinamento}

Conforme é citado na literatura, o treinamento da equipe de pesquisa torna-se fundamental para evitar vieses de performance e atrito relacionados com a forma como os usuários são captados para pesquisa (Sidani, 2013).

Nesta etapa, foi realizado o treinamento dos colaboradores do processo de rastreamento, o qual aconteceu em dois dias, com duração de 4 horas em cada encontro. Os temas abordados no treinamento foram:

* Abordagem dos usuários

* Leitura do manual do colaborador, elaborado previamente pela pesquisadora

* Preenchimento dos instrumentos

* Dúvidas mais frequentes em relação aos instrumentos

* Descrição dos pontos de coleta de dados: espaços coletivos da unidade

* Processo de randomização (ver detalhamento na etapa 4)

\subsubsection{Etapa 3 - Estudo piloto}

O estudo piloto foi realizado com 70 indivíduos escolhidos aleatoriamente e alocados nos grupos por processo de randomização.

\subsubsection{Etapa 4 - Rastreio}

Início do rastreio dos usuários no local da pesquisa. Este procedimento foi aplicado tanto no estudo piloto quanto no ensaio clínico. Cada usuário foi abordado dentro da unidade de APS, nos espaços coletivos, e indagado sobre o uso de álcool. Se a pessoa fazia uso de álcool, o colaborador procedia a aplicação dos instrumentos de rastreio (Audit) e o questionário de dados sociodemográficos. Caso o participante preenchesse os critérios de elegibilidade, ele podia ser incluído na pesquisa e convidado a assinar o termo de consentimento livre e esclarecido (TCLE) (Apêndice B). 


\subsubsection{Etapa 5 - Randomização}

Previamente ao início do rastreio, um dos colaboradores não envolvido no processo realizou dois sorteios no site randomization.com; o primeiro deles, com números de 1 a 70, para o estudo piloto e, o segundo, com números de 1 a 112, para o ensaio clínico. Uma vez gerada a lista com a alocação nos grupos, o colaborador colocou cada papel em um envelope opaco e devidamente lacrado, para serem entregues ao pesquisador principal, com o intuito de ocultar a alocação dos participantes, evitando assim o viés de seleção.

\subsubsection{Etapa 6 - Aplicação da intervenção breve grupal (GE) ou Cuidado Usual (GC) Grupo experimental $(\mathrm{GE})$}

Conforme alocação do usuário, foi realizado um convite para participar do grupo de intervenção (GE) em data e horário previamente estabelecidos, os quais possuíam múltiplas opções por dia, levando-se em consideração a disponibilidade dos usuários. Durante a intervenção, foi aplicada a técnica de intervenção breve grupal no modelo FRAMES, desenvolvida em uma única sessão (ver manual da intervenção).

\section{Grupo Controle (GC)}

Os participantes alocados no grupo controle foram orientados a continuarem com o atendimento padrão da unidade. Durante esse atendimento, que correspondia à consulta médica ou de enfermagem, era realizada uma pergunta do tipo dicotômica para os usuários sobre o uso da bebida alcoólica.

\subsubsection{Etapa 7 - Seguimento}

Foram realizadas duas avaliações posteriores à intervenção, em ambos os grupos (GE e GC), 30 e 90 dias, via telefone (Pinto, 2017). As ligações foram realizadas por um colaborador externo à pesquisa, diferente daquele que realizou o rastreio e sem conhecimento do grupo de alocação do participante, garantido assim o cegamento desse processo.

Durante as ligações, o avaliador aplicou o instrumento AUDIT e a RPM. Foram realizadas cinco tentativas de localizar o usuário telefonicamente; caso não fosse possível, entrou-se em contato com o pessoal da unidade de atenção primária, para se tentar localizar o usuário pessoalmente. Se, após essas tentativas de localização, não fosse possível entrar em contato com esse usuário, deveria se criar um registro, notificando tal incidente, sem retirar o participante do estudo. 


\subsubsection{Fluxograma da intervenção}

Figura 2. Fluxograma da intervenção breve grupal

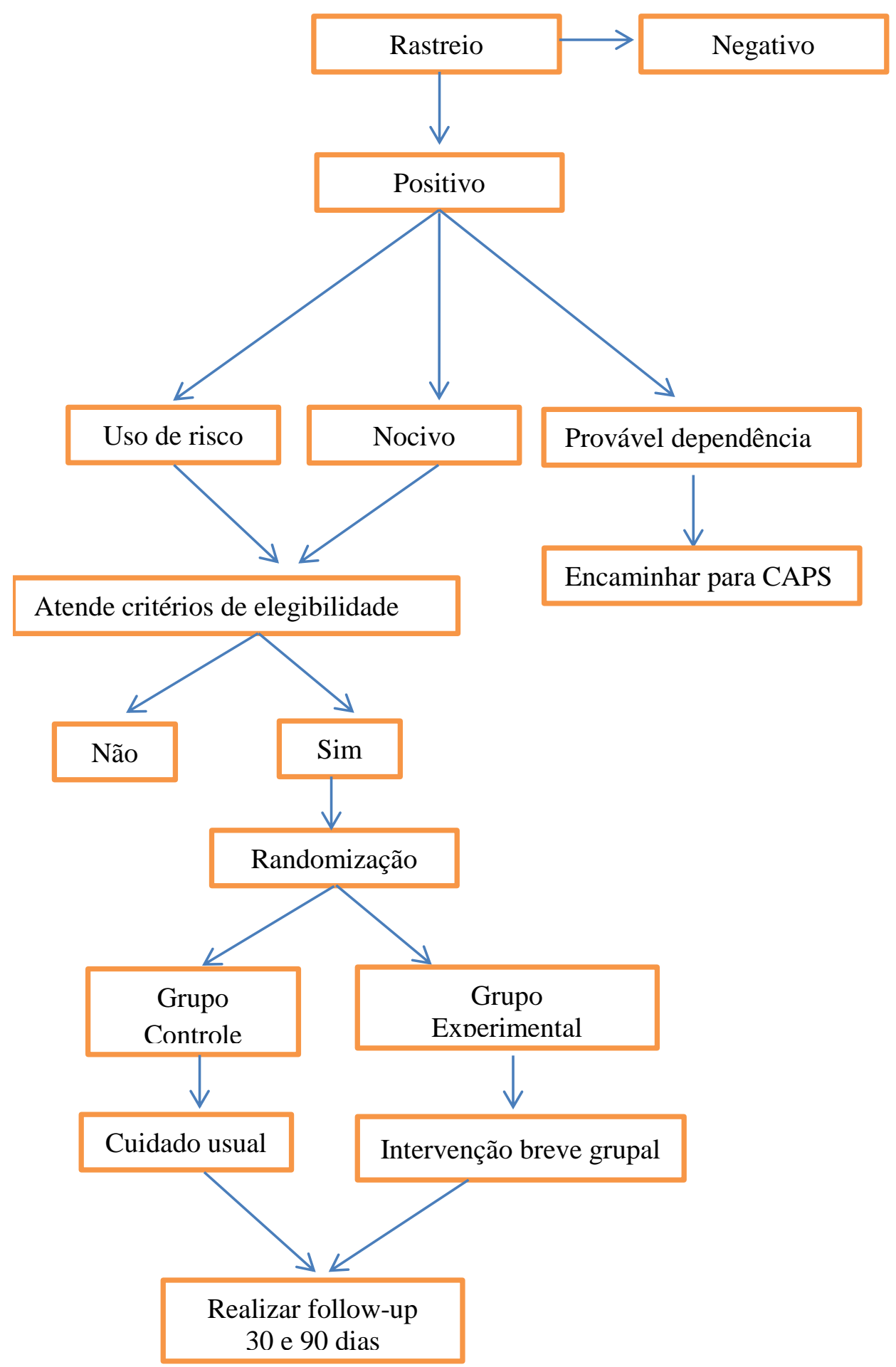




\subsection{Análise dos dados}

Os dados foram digitados e armazenados no programa Excel, utilizando o método de dupla entrada, para minimizar erros de digitação e posteriormente importados para análise no software R (versão 3.6.2). A fim de testar a homogeneidade dos grupos com relação às variáveis de caracterização iniciais, foi utilizado o teste Exato de Fisher, de varáveis categóricas, e o teste de Mann-Whitney, em casos de variáveis numéricas, tanto no estudo piloto quanto no ensaio clínico. Para avaliação da efetividade da IBG, utilizou-se a análise intragrupo e intergrupo, com método GEE (Generalized Equations Estimating), para ambos os estudos. A análise intragrupo consiste em comparar os tempos em cada um dos grupos, enquanto a análise intergrupo consiste em analisar a homogeneidade dos grupos em cada tempo.

Além disso, foi apresentado o Tamanho de Efeito (d de Cohen), que representa a diferença em desvios padrões entre as médias de dois grupos. Segundo Cohen (1988), d entre 0,20 e 0,50 representa tamanho de efeito pequeno; $d$ entre 0,50 e 0,80 representa tamanho de efeito médio e d superior a 0,80 representa tamanho de efeito grande. A evidência de hipóteses, foi avaliada com o Fator de Bayes (K). Assim, um valor de $\mathrm{K}$ entre 1 e 3,2 representa força de evidência fraca; $K$ entre 3,2 e 10 representa força de evidência substancial; K entre 10 e 100 representa força de evidência forte e $\mathrm{K}$ superior a 100 representa força de evidência decisiva.

\section{ASPECTOS ÉTICOS}

Os aspectos éticos deste estudo, em todas as suas etapas, foram garantidos pela aprovação do projeto pelo Comitê de Ética em Pesquisa da Escola de Enfermagem da Universidade de São Paulo, sob parecer 2.490.658, de 2018 (Anexo 2), pelo Comitê de Ética em Pesquisa da Secretaria Municipal da Saúde de São Paulo, sob parecer 2.565.764 (Anexo 3). Todos os participantes da pesquisa assinaram o Termo de Consentimento Livre Esclarecido, em conformidade com a Resolução 466, de 2012, a qual sustenta a pesquisa em seres humanos, segundo determinação do Conselho Nacional de Saúde e do Ministério da Saúde do Brasil. O estudo também consta no Registro Brasileiro de Ensaios . 
CAPITULO V 


\section{CONCLUSÕES}

Os resultados da presente investigação destacam a relevância do uso da IBG em homens que fazem uso de risco ou nocivo de álcool e que são atendidos em serviços de atenção primária à saúde. A revisão sistemática realizada constatou que se trata de uma intervenção com pouca evidência disponível no que diz respeito a sua efetividade. Como resultado do estudo piloto encontrou-se que a IBG é uma intervenção factível de ser aplicada no contexto da APS, salientando serem necessários ajustes para garantir uma melhor taxa participação dos indivíduos. O ensaio clínico realizado posteriormente, evidenciou que a IBG foi efetiva tanto na diminuição do uso problemático de álcool quanto no aumento da prontidão para mudança de comportamentos relacionados a esse uso na população masculina, indicando ainda que esta intervenção pode ser potencializada com o conhecimento prévio dos estágios de prontidão para mudança, já que estes apresentaram uma relação inversamente proporcional com o padrão de uso de álcool.

\section{IMPLICAÇÕES PARA PRÁTICA E PESQUISA}

Espera-se que os resultados desta pesquisa, tenham um impacto na visibilidade da IBG e de sua aplicabilidade nas rotinas de cuidado às pessoas que são atendidas diariamente nos serviços de APS, já que apresenta evidência inovadora, por ser o único estudo realizado no Brasil que visou explorar a relação da prontidão para mudança com o padrão de uso após exposição de uma população exclusivamente masculina à intervenção breve grupal no modelo FRAMES. A IBG pode ser aplicada por diversas categorias profissionais, desde que treinadas adequadamente no uso de instrumentos de detecção precoce e a aplicação da intervenção. Entretanto, espera-se que os profissionais de enfermagem que representam uma grande parcela de trabalhadores nos serviços de saúde possam obter o maior benefício com a IBG, sem esquecer que o enfermeiro tem um papel fundamental na articulação de outros profissionais tornando-se um instrumento de difusão do uso da IBG entre os profissionais que trabalham na unidade de APS.

No que diz respeito as implicações para futuras pesquisas, sugere-se a reprodução deste estudo em outras unidades de atenção primária a saúde do território brasileiro, estendendo-o a populações mais diversas, com o intuito de superar as limitações aqui apontadas, acrescentar evidências mais robustas da efetividade da IBG e o seu comportamento frente à diversidade dos serviços de APS no Brasil. Como consequência disso, tais ações podem-se transformar em recursos que auxiliem futuros processos de implementação da IBG, pois trata-se de um recurso valioso, de fácil aquisição e economicamente viável no contexto da APS. 
REFERENCIAS 


\section{Referências}

Babor TF, Higgins-Biddle JC. Alcohol screening and brief intervention: dissemination strategies for medical practice and public health. Addiction. 2000;95(5):677-86.

Babor TF, Mcree BG, Kassebaum P, Grimaldi PL, Ahmed K. Screening, Brief Intervention, and Referral to Treatment (SBIRT): Toward a Public Health Approach to the Management of Substance Abuse. Subst Abus. 2007;7077:7-30.

Ballesteros J, Duffy JC, Querejeta I, Ariño J, Gonzalez-Pinto A. Efficacy of Brief Interventions for Hazardous Drinkers in Primary Care: Systematic Review and Meta-Analyses. Alcohol Clin Exp Res. 2004;28(4):608-18. Available from: http://doi.wiley.com/10.1097/01.ALC.0000122106.84718.67

Bernstein MH, Baird GL, Yusufov M, Mastroleo NR, Carey KB, Graney DD, et al. A novel approach for streamlining delivery of brief motivational interventions to mandated college students: using group and individual sessions matched to level of risk. Subst Use Misuse. 2017;52(14):1883-91. Available from: http://www.ncbi.nlm.nih.gov/pubmed/28812420

Bien TH, Miller WR, Tonigan JS. Brief interventions for alcohol problems: a review. Addiction. 1993;88(3):315-36. Available from: http://doi.wiley.com/10.1111/j.13600443.1993.tb00820.x

Brito R, Santos D, Maciel P. Male view about the assistence care in the family health strategy. Rev RENE. 2010;11(4):135-42.

Capaldi DM, Tiberio SS, Washburn IJ, Yoerger K, Feingold A. Growth, persistence, and desistance of alcohol use for at-risk men in their 30s. Alcohol Clin Exp Res. 2015;39(7):120311. Available from: http://doi.wiley.com/10.1111/acer.12748

Chafetz M, Blane H, Abram H, Golner J, Lacy E, McCourt W, et al. Establishing treatment relations with alcoholics. J Nerv Ment Dis [Internet]. 1962;134:395-409. Available from: https://www.ncbi.nlm.nih.gov/pubmed/14141896

Clossick E, Woodward S. Effectiveness of alcohol brief interventions in general practice. $\mathrm{Br} \mathrm{J}$ Nurs. 2014;23(11):574-80. Available from: doi: 10.12968/bjon.2014.23.11.574

Costa PHA, Belchior DCM, Cruvinel E, Santana F de P, Ronzani TM. Developing a method of implementation of screening, brief intervention, and referral to treatment in primary health care settings of Brazil and Latin America. Addict Sci Clin Pract. 2013;8(Suppl 1). Available from: 
doi:10.1186/1940-0640-8-S1-A6

Costa PHA da, Mota DCB, Cruvinel E, Santana F de P, Ronzani TM. Metodologia de implementação de práticas preventivas ao uso de drogas na atenção primária latino-americana. Rev Panam Salud Pública. 2013;33(5):325-31. Available from: doi:10.1590/S102049892013000500003

Datasus. Sistema de informação de atenção básica. 2015.

De Visser RO, Smith JA. Alcohol consumption and masculine identity among young men. Psychol Health. 2007;22(5):595-614. Available from: http://www.tandfonline.com/doi/abs/10.1080/14768320600941772

Elzerbi C, Donoghue K, Drummond C. A comparison of the efficacy of brief interventions to reduce hazardous and harmful alcohol consumption between European and non-European countries: a systematic review and meta-analysis of randomized controlled trials. Addiction. 2015;110(7):1082-91. Available from: http://doi.wiley.com/10.1111/add.12960

Flórez L, Gantiva CA. Brief motivational therapy: Differences between individual and group application for the moderation in alcohol consumption and other psychological variables associated with change. Acta Colomb Psicol. 2009;12(1):13-26. Available from: http://www.scielo.org.co/scielo.php?script=sci_arttext\&pid=S0123-

91552009000100002\&lng=en\&nrm=iso\%3E. ISSN 0123-9155

Formigoni MLO, de Lacerda RB, Vianna VPT, Ronzani TM, Carneiro AP. Intervenção breve: módulo 4. In: SUPERA: Sistema para detecção do Uso abusivo e dependência de substâncias Psicoativas: Encaminhamento, intervenção breve, reinserção social e acompanhamento. 11. ed. - Brasília. Secretaria Nacional de Políticas sobre Drogas, 2017.

Gomes R, Moreira MCN, Nascimento EF do, Rebello LEF de S, Couto MT, Schraiber LB. Os homens não vêm! Ausência e/ou invisibilidade masculina na atenção primária. Cien Saude Colet. 2011;16(suppl 1):983-92. Available from: http://www.scielo.br/scielo.php?script=sci_arttext\&pid=S1413$\underline{81232011000700030 \& \operatorname{lng}=p t \& t \operatorname{lng}=p t}$

Gossage J, Snell C, Parry C, Marais AS, Barnard R, de Vries M, et al. Alcohol use, working conditions, job benefits, and the legacy of the "dop" system among farm workers in the western Cape province, South Africa: hope despite high levels of risky drinking. Int J Environ Res Public Health. 2014;11(7):7406-24. Available from: doi: 10.3390/ijerph110707406 
Grimes DA, Schulz KF. An overview of clinical research: the lay of the land. Lancet [Internet]. 2002;359(9300):57-61. Available from: http://linkinghub.elsevier.com/retrieve/pii/S0140673602072835

Van Horn DHA, Bux DA. A pilot test of motivational interviewing groups for dually diagnosed inpatients. J Subst Abuse Treat. 2001;20(2):191-5. Available from: doi: 10.1016/S07405472(00)00157-4

Humeniuk R, Ali R, Babor T, Souza-Formigoni MLO, de Lacerda RB, Ling W, et al. A randomized controlled trial of a brief intervention for illicit drugs linked to the Alcohol, Smoking and Substance Involvement Screening Test (ASSIST) in clients recruited from primary health-care settings in four countries. Addiction. 2012;107(5):957-66. Available from: http://doi.wiley.com/10.1111/j.1360-0443.2011.03740.x

INPAD. Consumo de Álcool no Brasil Tendências entre 2006/2012. 2013. Available from: http://inpad.org.br/wp-content/uploads/2013/04/LENAD_ALCOOL_Resultados-

Preliminares.pdf

Lesch E, Casper R. 'Drinking with respect': Drinking constructions of men who live in a Cape Winelands farm community in South Africa. J Health Psychol. 2017;22(4):409-21. Available from: http://journals.sagepub.com/doi/10.1177/1359105315603476

Lima CT, Freire ACC, Silva APB, Teixeira RM, Farrell M, Prince M. Concurrent and construct validity of the audit in an urban Brazilian sample. 2005;40(6):584-9. Available from: doi: 10.1093/alcalc/agh202

Lock CA, Kaner E, Heather N, Doughty J, Crawshaw A, McNamee P, et al. Effectiveness of nurse-led brief alcohol intervention: a cluster randomized controlled trial. J Adv Nurs. 2006;54(4):426-39. Available from: http://doi.wiley.com/10.1111/j.1365-2648.2006.03836.x

Madras BK, Compton WM, Avula D, Stegbauer T, Stein JB, Clark HW. Screening, brief interventions, referral to treatment (SBIRT) for illicit drug and alcohol use at multiple healthcare sites: Comparison at intake and 6 months later. Drug Alcohol Depend. 2009;99(13):280-95. Available from: http://linkinghub.elsevier.com/retrieve/pii/S0376871608003104

Matheson C, Pflanz-Sinclair C, Almarzouqi A, Bond CM, Lee AJ, Batieha A, et al. A controlled trial of screening, brief intervention, and referral for treatment (SBIRT) implementation in primary care in the United Arab Emirates. Prim Health Care Res Dev. 2017;1-11. Available from:https://www.cambridge.org/core/product/identifier/S1463423617000640/type/journal_ar 
ticle

McCambridge J, Cunningham JA. The early history of ideas on brief interventions for alcohol. Addiction. 2014;109(4):538-46. Available from: http://doi.wiley.com/10.1111/add.12458

Melchers M, Montag C, Reuter M, Spinath FM, Hahn E. How heritable is empathy? Differential effects of measurement and subcomponents. Motiv Emot. 2016;40(5):720-30. Available from: http://link.springer.com/10.1007/s11031-016-9573-7

Méndez E. Uma versão Brasileira do AUDIT. [Tese] Universidade Federal de Pelotas; 1999.

Miller WR, Rollnick S. Entrevista motivacional: Preparando as pessoas para a mudança de comportamentos adictivos. 1st ed. Artmed, editor. Porto Alegre; 2001.

Ministerio da saúde do Brasil. Política nacional de atenção integral à saúde do homem. Brasil; 2008 p. 40.

Ministério da Saúde do Brasil, Secretaria de Vigilância em saúde, Departamento de Vigilância de Doenças e Agravos não transmissíveis e promoção da saúde. Vigitel Brasil 2016: vigilância de fatores de risco e proteção para doenças crônicas por inquérito telefônico : estimativas sobre frequência e distribuição sociodemográfica de fatores de risco e proteção para doenças crônicas nas capitais dos 26 estados b. Brasília; 2017.

Ministerio de saúde do Brasil. Perfil da situação de saúde do homem no Brasil. Brasília; 2012.

Minto EC, Corradi-Webster CM, Gorayeb R, Laprega MR, Furtado EF. Intervenções breves para o uso abusivo de álcool em atenção primária. Epidemiol e Serviços Saúde. 2007;16(3):207-20. Available from: http://scielo.iec.pa.gov.br/scielo.php?script=sci_arttext\&pid=S167949742007000300007\&lng=pt\&nrm=iso\&tlng=pt

Moretti-Pires RO, Corradi-Webster CM. Adaptação e validação do Alcohol Use Disorder Identification Test (AUDIT) para população ribeirinha do interior da Amazônia, Brasil. Cad Saude Publica. 2011;27(3):497-509. Available from: http://www.scielo.br/scielo.php?script=sci_arttext\&pid=S0102$311 \times 2011000300010 \& \operatorname{lng}=\mathrm{pt} \& \operatorname{lng}=\mathrm{pt}$

Nelson JP, McNall AD. Alcohol prices, taxes, and alcohol-related harms: A critical review of natural experiments in alcohol policy for nine countries. Health Policy (New York). 2016;120(3):264-72. Available from: http://www.ncbi.nlm.nih.gov/pubmed/26861971 
Nolen-Hoeksema S. Gender differences in risk factors and consequences for alcohol use and problems. Clin Psychol Rev. 2004;24(8):981-1010. Available from: http://linkinghub.elsevier.com/retrieve/pii/S0272735804001047

Organização Panamericana da Saúde. Crece el consumo nocivo de alcohol en las Américas. 2015.

Organización Panamericana de la Salud. Informe de situación regional sobre el alcohol y la salud en las Américas. Washington, DC; 2016. p. 74.

Parfrey P, Barret B. Clinical Epidemiology: Practice and Methods [Internet]. 2nd ed. Parfrey PS, Barrett BJ, editors. New York, NY: Springer New York; 2015. Available from: http://link.springer.com/10.1007/978-1-4939-2428-8

Pereira MO, Anginoni BM, Ferreira N da C, Oliveira MAF de, Vargas D de, Colvero L de A. Effectiveness of the brief intervention for the use of abusive alcohol in the primary: systematic review. Rev Bras Enferm. 2013;66(3):420-8. Available from: http://www.scielo.br/scielo.php?script=sci_arttext\&pid=S0034-

$71672013000300018 \& \operatorname{lng}=\mathrm{en} \& \mathrm{nrm}=\mathrm{iso} \& \mathrm{t} \operatorname{lng}=\mathrm{pt}$

Peres PDO, Dos Santos WJ, Viegas SM, Da Silveira EAA, Bezerra AR. Experience of men in the context of Primary Health Care. Investig y Educ en Enfermería. 2015;33(2):227-36. Available from: doi: 10.1590/S0120-53072015000200005

Pinto S. Intervenção com familiares, usuários de álcool e álcool mais outras drogas: um estudo clínico. [Tese] Escola de Enfermagem Universidade de São Paulo; 2017.

Ronzani TM, Ribeiro MS, Amaral MB do, Formigoni MLO. Implantação de rotinas de rastreamento do uso de risco de álcool e de uma intervenção breve na atenção primária à saúde: dificuldades a serem superadas. Cad Saude Publica. 2005;21(3):852-61. Available from: http://www.scielo.br/scielo.php?script=sci_arttext\&pid=S0102-

$311 X 2005000300019 \& \operatorname{lng}=$ pt\&nrm=iso\&tlng=pt

Ronzani TM, Rodrigues TP, Batista AG, Lourenço LM, Formigoni MLO. Estratégias de rastreamento e intervenções breves para problemas relacionados ao abuso de álcool entre bombeiros. Estud Psicol. 2007;12(3):285-90. Available from: http://www.scielo.br/scielo.php?script=sci_arttext\&pid=S1413- 
Santos WS, Gouveia VV, Fernandes DP, Souza SSB De, Grangeiro ASDM. Alcohol Use Disorder Identification Test (AUDIT): explorando seus parâmetros psicométricos. J Bras Psiquiatr. 2012;61(3):117-23. Available from: http://www.scielo.br/scielo.php?script=sci_arttext\&pid=S0047$20852012000300001 \& \operatorname{lng}=$ pt\&tlng=pt

Saunders JB, Aasland OG, Amundsen A, Grant M. Alcohol consumption and related problems among primary health care patients: WHO Collaborative project on early detection of persons with harmful alcohol consumption-I. Addiction. 1993;88(3):349-62. Available from: http://doi.wiley.com/10.1111/j.1360-0443.1993.tb00822.x

Saunders JB, Aasland OG, Babor TF, De la Fuente JR, Grant M. Development of the Alcohol Use Disorders Identification Test (AUDIT): WHO Collaborative Project on Early Detection of Persons with Harmful Alcohol Consumption-II. Addiction. 1993;88(6):791-804. Available from: http://doi.wiley.com/10.1111/j.1360-0443.1993.tb02093.x

Sidani S, Braden CJ. Design, evaluation, and translation of nursing interventions. Canada; 2013.

Soares J, Vargas D. Effectiveness of brief group intervention in the harmful alcohol use in primary health care. Rev Saude Publica. 2019;53:4. Available from: https://www.revistas.usp.br/rsp/article/view/154071

Sobell L, Sobell M. Terapia de Grupo para transtornos por abuso de substâncias: abordagem cognitivo-comportamental motivacional. 1st ed. Artmed, editor. Porto Alegre; 2013.

Strobbe S. Prevention and screening, brief intervention, and referral to treatment for substance use in primary care. Prim Care Clin Off Pract. 2014;41(2):185-213. Available from: http://dx.doi.org/10.1016/j.pop.2014.02.002

Studer J, Baggio S, Deline S, N'Goran AA, Henchoz Y, Mohler-Kuo M, et al. Peer pressure and alcohol use in young men: A mediation analysis of drinking motives. Int J Drug Policy. 2014;25(4):700-8. Available from: http://linkinghub.elsevier.com/retrieve/pii/S0955395914000267

World Health Organization. Cuestionario de Identificación de los Transtornos debidos al Consumo de Alcohol. 2001. Available from: http://www.who.int/substance_abuse/activities/en/AUDITmanualSpanish.pdf 
World Health Organization. Global Status Report on alcohol and health [Internet]. OMS. 2014 [cited 2015 Mar 11]. Available from: http://apps.who.int/iris/bitstream/10665/112736/1/9789240692763_eng.pdf

World Health Organization. Global status report on alcohol and health 2018. Geneva; 2018. 
APÊNDICES 


\title{
Apêndices
}

\section{Apêndice A}

\section{Questionário Sociodemográfico, clínico e comportamental (Estudo piloto)}

\author{
N. ${ }^{\circ}$ do Voluntário:
}

1-Idade:

2-Sexo: (1) Masculino (2) Feminino

3-Cor: (1) Branco (2) Pardo (3) Preto (4) Amarelo

4-Estado Conjugal:

(1) Solteiro (2) Casado (3) Divorciado/Separado (4) Viúvo (5) Amasiado

5- Religião:

6-Escolaridade:
(1) Analfabeto
(6) Superior incompleto
(2) $1^{\circ}$ grau incompleto
(7) Superior completo
(3) $1^{\circ}$ grau completo
(8) Outro. Especificar:

(4) $2^{\circ}$ grau incompleto

(5) $2^{\circ}$ grau completo

7-Ocupação:
(1) Nenhuma
(2) Estudante
(3) Aposentado
(4) Empregado

(5) Cargos Administrativos

(6) Outros (bicos etc.)

8-Trabalhou no último ano:
(1) Tempo integral
9 - Vive em situação de rua?
(2) Tempo Parcial
(1) Não
(3) Não Trabalhou
(2) $\mathrm{Sim}$
(4)
10 - Número de pessoas na família:

Outro:

11-Renda Familiar por classe social:

Classe salários mínimos (sm) renda familiar (r\$)
(1) A
Acima 20 SM R\$ 14.500 ou mais

(2) $\mathrm{B}$

10 a 20 SM De $\mathrm{R} \$ 7.250,00$ a $\mathrm{R} \$ 14.499,99$

(3) $\mathrm{C}$

4 a 10 SM De R $\$ 2.900,00$ a R $\$ 7.249,99$

(4) D

2 a 4 SM De R\$1.450,00 a R\$2.899,99

(5) $\mathrm{E}$

Até 2 SM Até R\$ 1.449,99

(6) Não tem

(7) Não sabe

14 - Você faz uso de bebidas alcoólicas? Se sim, você bebeu em média quantas doses por semana, nos últimos 90 dias?

Faz algum tipo de tratamento? Qual? 


\section{Questionário Sociodemográfico, clínico e comportamental (ECR)}

$\mathbf{N}^{\circ}$ do Voluntário:

1. Idade:

2. Vc é cadastrado nesta unidade de saúde? (UBS) 1. Sim ( ) 2. Não ( )

3. Sexo: (1) Masculino (2) Feminino (3) Intersexual

4. Identidade de Gênero: (Você se sente homem ou mulher?).

(1) Mulher (2) Homem (3) Outros:

5. Orientação Sexual: (Você se relaciona com homem ou mulher?)

(1) Assexual (2) Bissexual (3) Heterossexual (4) Homossexual (5) Pansexual

5. Nacionalidade: (1) Brasileira (2) Outros:

6. Mora na cidade de São Paulo: (1) Sim (2) Não

7. Qual você considera a cor da sua pele o sua raça/etnia:

(1) Branca (2) Parda (3) Preta (4) Amarela (5) Indígena (6) Não declara

8. Estado conjugal:

(1) Solteiro (2) Casado (3) Divorciado/Separado (4) Viúvo (5) Amasiado

9. Religião:

Escolaridade: (Até qual serie você fez?).

(1) Não alfabetizado

(2) $1^{\circ}$ Grau incompleto

(3) $1^{\circ}$ Grau completo (Até 8 serie)

(4) $2^{\circ}$ Grau incompleto

(5) $\quad 2^{\circ}$ Grau completo (Ensino médio)
(6) Curso Técnico

(7) Superior Incompleto

(8) Superior Completo

(9) Pós Graduação

10. Situação laboral. Marque com $\mathbf{X}$ a atividade principal:

(1)Empregado com carteira assinada

(5) Aposentado

(2)Empregado sem carteira assinada

(6) Não declara (bico)

(3)Autônomo

(7) Desempregado

(4)Estudante

(8) Outros

11. Tipos de moradia
(1) Albergue/Centro de acolhida
(5) "Maloca"
(2) Própria
(6) Ocupação
(3) Aluguel
(7) Pensão
(4) Rua
(8) República

12. Renda Individual: Não declara:

13. Quais atividades você geralmente realiza nos seus momentos de lazer?

(1) Visitar amigos e familiares (2) Festa (3) passear com a família (4) Atividade física

(5) Outros:

14. Tem algum problema de saúde? (1) Sim (2) Não

Se sim, qual?

15. Você faz algum tratamento para Saúde Mental? (1) Sim (2) Não

16. Motivo do tratamento?

17. Faz uso de alguma droga ilícita? (1) Sim (2) Não

18. Qual?

19. Fuma tabaco? (1) Sim (2) Não Frequência

20. Quais ocasiões nas que realiza uso da bebida: 


\section{Apêndice B}

\section{Termo de Consentimento Livre e Esclarecido, TCLE.}

Você está sendo convidado a participar da pesquisa intitulada "Intervenção breve grupal para redução do padrão de uso de álcool em homens de uma unidade de atenção primária à saúde: ensaio clínico randomizado", desenvolvida pela pesquisadora Erika Gisseth León Ramírez com o objetivo de verificar o efeito de uma intervenção na redução do uso de álcool em homens usuários de serviços de atenção primária à saúde.

Caso você aceite participar da pesquisa, irá responder a um questionário de dados sociodemográficos, um instrumento sobre o uso de álcool e uma escala numérica sobre motivação para mudança de comportamento. Dependendo da sua pontuação no instrumento sobre uso de álcool, você será classificado em quatro diferentes categorias: "Abstinente/não risco", "Uso de risco", "Uso nocivo" e "Provável dependência".

Se você for classificado como usuário "abstinente" ou "não risco", sua participação envolverá uma orientação dos pesquisadores sobre o consumo de álcool.

Caso você seja classificado como usuário de "uso de risco ou nocivo de álcool", você será convidado participar de um sorteio entre dois grupos, o grupo CONTROLE e o grupo INTERVENÇÃOO.

Caso você seja sorteado para o grupo CONTROLE, sua participação envolverá uma orientação simples sobre o uso de álcool por meio de um folheto explicativo. Caso você seja sorteado para o grupo INTERVENÇÃO, sua participação envolverá comparecer a uma única intervenção com a enfermeira pesquisadora, onde será conversado sobre o uso de álcool. $\mathrm{O}$ encontro será realizado grupalmente em uma sala reservada e terá duração de aproximadamente 35 minutos. Para efeitos de verificar a aplicação adequada da intervenção, as sessões serão gravadas em áudio.

Em ambos os grupos serão realizadas ligações dentro de 30 dias e 90 dias para responder questões de acompanhamento da pesquisa. A duração das entrevistas telefónica será de aproximadamente 10 minutos. No grupo experimental será realizada uma entrevista pessoal 90 dias após intervenção para indagar sobre o significado que ela teve na vida das pessoas que participaram. Sua participação na pesquisa contribuirá na construção de ações de prevenção do uso de álcool na atenção primária à saúde. É possível que você sinta algum desconforto do tipo emocional, decorrente da evocação de sentimentos, emoções e lembranças durante o atendimento. Caso isso ocorra, os pesquisadores estarão à disposição para atender essa situação, por favor, informe para que o processo seja interrompido de imediato.

Sua participação neste estudo é totalmente voluntária, pode deixar de responder aos instrumentos no momento que assim o considere necessário sem ter que fornecer explicações sobre essa decisão, já que não ocorrerá nenhum tipo de consequência negativa.

Para aquelas pessoas que forem selecionadas para o grupo intervenção, será oferecido o dinheiro do transporte público utilizado (ida e volta: $\mathrm{R} \$ 7,60)$ que será entregue após o agendamento do encontro, o pagamento será realizado quantas vezes forem necessárias, de acordo com o número de vezes de idas ao serviço.

Finalmente, caso você seja classificado como usuário com "provável dependência" de álcool, você será encaminhado para o Centro de Atenção Psicossocial - Álcool e outras Drogas, serviço de referência em saúde mental, onde o pesquisador irá orientar sobre os horários de atendimento e benefícios do serviço, sendo a escolha de procurar o serviço estritamente sua.

As informações obtidas serão analisadas em conjunto, não sendo divulgada a identificação de nenhum participante da pesquisa, garantindo, assim, o seu anonimato e a privacidade da sua participação. Deixa-se explícito também que, com exceção das pessoas selecionadas para aplicar a intervenção, a presente pesquisa não representará gastos ou despesas para você. No entanto, caso seja necessário, haverá garantia de indenização diante de eventuais 
danos decorrentes da pesquisa

Você pode tirar suas dúvidas sobre o projeto e sua participação, agora ou a qualquer momento com:

Erika Gisseth León Ramírez, e-mail: egleonr@usp.br - pesquisador responsável; Tel. (11) 97764-9883 - Escola de Enfermagem da Universidade de São Paulo- Departamento de Enfermagem Materna infantil e psiquiátrica- Sala 234, situada na Av. Enéas de Carvalho Aguiar, 419. Para esclarecimentos de dúvidas ou denúncias éticas relacionadas a essa pesquisa você poderá contatar:

Comitê de Ética em Pesquisa (CEP) - Endereço - Av. Dr. Enéas de Carvalho Aguiar, 419 Cerqueira César - São Paulo/SP CEP - 05403-000 Telefone- (11) 30618858 e-mail cepee@usp.br

Este documento deve ser rubricado em todas as suas páginas e assinado nas duas vias, sendo que, o participante da pesquisa receberá uma via do Termo de Consentimento Livre e Esclarecido assinada e rubricada pelo pesquisador.

Desde já meus sinceros agradecimentos por sua colaboração.

\section{Erika Gisseth León Ramírez}

Pesquisador Responsável-Universidade de São Paulo

Caso você tenha compreendido as informações e concorde em participar, assine na sequência.

Assinatura: Data: 


\section{Apêndice C}

Ficha de agendamento para Intervenção breve grupal

Data:

Nome completo:

Telefone Fixo: Celular:

Endereço:

Tem algum profissional de referência dentro da UBS:

Dia disponível para participar da intervenção:

Horário de preferência para participar da intervenção 


\section{Apêndice D}

\section{SBIRT Checklist}

\section{Componente de rastreio (Screening)}

1.Utiliza um instrumento completo para rastreio

2.Estabelece um ambiente adequado para a sessão

3.Garante a confidencialidade da informação

4.Define claramente os parâmetros de uso de álcool

5.Usa a linguagem do paciente durante o rastreio

6.Realiza a classificação adequada do paciente

\section{Componentes Intervenção breve}

1.Estabelece ambiente adequado e introduz a sessão

2.Retoma o score do instrumento com o paciente

3.Discute o resultado do instrumento com o paciente

4.Describe o risco que implica o uso nocivo de álcool

5.Promove a responsabilidade pessoal e a escolha

6.Faz aconselhamento sobre manter ou reduzir o uso da substância inclusive a abstinência.

7.Oferece um menu de opções

8.Utiliza a balança decisória ou prós e contras

9.Ayuda ao paciente a estabelecer uma meta

10.Oferece material de apoio para levar para casa

11.Expressa empatia

12.Diminui a resistência

13.Desenvolve a discrepância

14.Promove a autoeficácia

15.Encerra sumarizando a sessão
Sim Não NA

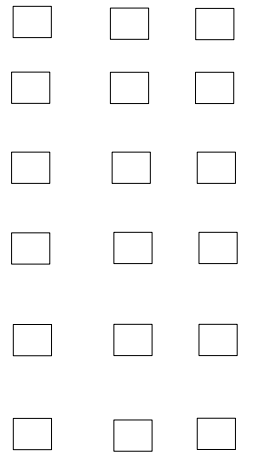


ANEXOS 
Anexos

Anexo 1

AUDIT (Alcohol Use Disorders Identification Test)

\section{AUDIT - Teste para Identificaçāo de Problemas Relacionados ao Uso de Álcool}

\begin{tabular}{|c|c|}
\hline $\begin{array}{l}\text { 1. Com que frequência você consome bebidas } \\
\text { alcoólicas? } \\
\text { (0) Nunca [vá para as questōes 9-10] } \\
\text { (1) Mensalmente ou menos } \\
\text { (2) De } 2 \text { a } 4 \text { vezes por mês } \\
\text { (3) De } 2 \text { a } 3 \text { vezes por semana } \\
\text { (4) } 4 \text { ou mais vezes por semana }\end{array}$ & $\begin{array}{l}\text { 6. Quantas vezes ao longo dos últimos } 12 \text { meses vocé } \\
\text { precisou beber pela manhä para poder se sentir bem ao } \\
\text { longo do dia após ter bebido bastante no dia anterior? } \\
\text { (0) Nunca } \\
\text { (1) Menos do que uma vez ao mês } \\
\text { (2) Mensalmente } \\
\text { (3) Semanalmente } \\
\text { (4) Todos ou quase todos os dias }\end{array}$ \\
\hline $\begin{array}{l}\text { 2. Quantas doses alcoólicas você consome tipicamente } \\
\text { ao beber? } \\
\text { (0) } 0 \text { ou } 1 \\
\text { (1) } 2 \text { ou } 3 \\
\text { (2) } 4 \text { ou } 5 \\
\text { (3) } 6 \text { ou } 7 \\
\text { (4) } 8 \text { ou mais }\end{array}$ & $\begin{array}{l}\text { 7. Quantas vezes ao longo dos últimos } 12 \text { meses você se } \\
\text { sentiu culpado ou com remorso depois de ter bebido? } \\
\text { (0) Nunca } \\
\text { (1) Menos do que uma vez ao mês } \\
\text { (2) Mensalmente } \\
\text { (3) Semanalmente } \\
\text { (4) Todos ou quase todos os dias }\end{array}$ \\
\hline $\begin{array}{l}\text { 3. Com que frequência você consome cinco ou mais } \\
\text { doses de uma vez? } \\
\text { (0) Nunca } \\
\text { (1) Menos do que uma vez ao mês } \\
\text { (2) Mensalmente } \\
\text { (3) Semanalmente } \\
\text { (4) Todos ou quase todas os dias } \\
\text { Se a soma das questōes } 2 \text { e } 3 \text { for } 0 \text {, avance para as } \\
\text { questōes } 9 \text { e } 10\end{array}$ & $\begin{array}{l}\text { 8. Quantas vezes ao longo dos últimos } 12 \text { meses vocé foi } \\
\text { incapaz de lembrar o que aconteceu devido à bebida? } \\
\text { (0) Nunca } \\
\text { (1) Menos do que uma vez ao mês } \\
\text { (2) Mensalmente } \\
\text { (3) Semanalmente } \\
\text { (4) Todos ou quase todos os dias }\end{array}$ \\
\hline $\begin{array}{l}\text { 4. Quantas vezes ao longo dos últimos } 12 \text { meses vocé } \\
\text { achou que não conseguiria parar de beber uma vez } \\
\text { tendo começado? } \\
\text { (0) Nunca } \\
\text { (1) Menos do que uma vez ao més } \\
\text { (2) Mensalmente } \\
\text { (3) Semanalmente } \\
\text { (4) Todos ou quase todos os dias }\end{array}$ & $\begin{array}{l}\text { 9. Você já causou ferimentos ou prejuizos a você mesmo } \\
\text { ou a outra pessoa após ter bebido? } \\
\text { (0) Nẫo } \\
\text { (2) Sim, mas nâo nos últimos } 12 \text { meses } \\
\text { (4) Sim, nos últimos } 12 \text { meses Se o total for maior do que o } \\
\text { ponto de corte recomendado, } \\
\text { consulte o manual. }\end{array}$ \\
\hline $\begin{array}{l}\text { 5. Quantas vezes ao longo dos últimos } 12 \text { meses você, } \\
\text { por causa do álcool, não conseguiu fazer o que era } \\
\text { esperado de você? } \\
\text { (0) Nunca } \\
\text { (1) Menos do que uma vez ao mês } \\
\text { (2) Mensalmente } \\
\text { (3) Semanalmente } \\
\text { (4) Todos ou quase todos os dias }\end{array}$ & $\begin{array}{l}\text { 10. Algum parente, amigo ou médico já se preocupou com } \\
\text { o fato de você beber ou sugeriu que você parasse? } \\
\text { (0) Nẫo } \\
\text { (2) Sim, mas nẫo nos últimos } 12 \text { meses } \\
\text { (4) Sim, nos últimos } 12 \text { meses } \\
\text { Se o total for maior do que o ponto de corte recomendado, } \\
\text { consulte o manual. }\end{array}$ \\
\hline
\end{tabular}

Resultado:

Classificaçăo: zona 1 : ate 7 pontos: indica uso de babxo fisco ou abstinéncia zona II: de 8 a 15 pontos: indica uso de risco

zona III: de 16 a 19 pontos: sugere uso nocivo ou prejudicial zona IV: acima de 20 pontos: sugere uma possîvel dependência 
Aprovação Comitê de Ética em Pesquisa da Escola de Enfermagem da Universidade de São Paulo

\begin{tabular}{|l|l|l|l|l}
\hline EE & USP - ESCOLA DE \\
ENFERMAGEM DA \\
UNIVERSIDADE DE SÃO
\end{tabular}

\section{PARECER CONSUBSTANCIADO DO CEP}

\section{DADOS DO PRONETO DE PESQUI3A}

Titulo da Pocquica: intervençbo breve grupal para reduç\$o do padrbo de uso de sicool em homena: ensalo clinico randomizado

Pocqulcador: DIVANE DEVARGAB

Area Tematioa:

Vercso: 2

CAAE: 80385817.7 .0000 .5392

Inctitulọso Proponente: Escola de Enfermagem da Univerzldade de ASo Paulo - EEUaf

Patroolnador Prindpal: Financlamento Proprio

DADOS DO PARECER

Número do Pareoer: 2.490.658

Aprocentagso do Projoto:

Trata-se de uma pesqusa de doutorado da aluna Erika Gleseth Leon Ramirez orientada peio Prot Dr Dlvane de Vargas que tem como foco o uso noclvo do alcool, que representa uma problematica mundlal, eapeciaimente entre homena. A poirica nacional de atençás integral a saude do homem pretendeu-se garantir o acesso desta populaç50 acs servigos de saode; entretanto, easa aceaslbilidade ainda mostra-se prejudicada. Dentre as eztrateglas preconizadas pela Organizaçlo Mundlal da aaude para reduçblo do uso noclvo de alcool na populaç\$o masculina na atenç5o primaria a saude encontra-se a tecnica BBIRT, defnida peio Substance Abuse and Mental Hearth Services Administration (BAMHBA). O programa SBIRT visa a obtenç\$o do bem-eztar de um individuo, grupo ou comunidade e que possul um numero de componentes que aumenta seu nivel de complexidade nas suas Interaçbes, execuçbo e avallaç5o. Oa eiementos que do agIRT aSo rastreio, intervençbo breve (utllzaç\$o do modelo FRAMEa, traduzido para o portugues como ADERIR) e encaminhamento. Neste contexto, eate eatudo tem a intenç5o de reaponder a seguinte pergunta de pesquas: a Intervençlo breve grupal com o modeio FRAMEa tem impacto na mudança do padr5́o de uso em homens com uso de riaco e noclvo de alcool no ambito da atençbio primaria a saude? Para tanto, sera desenvolvido um ensalo clinico de intervenç5o complexa com dlatribulçbo randomica paralelo em dols grupos. Os dados serbo coletados nas Instalaçbes da unidade de atençbio primaria a saude se. $O$ eatudo serd composto por homens ususrios de aicool que frequentam a unidade de atença primaria a saude, que preencham oa seguintes criterios de

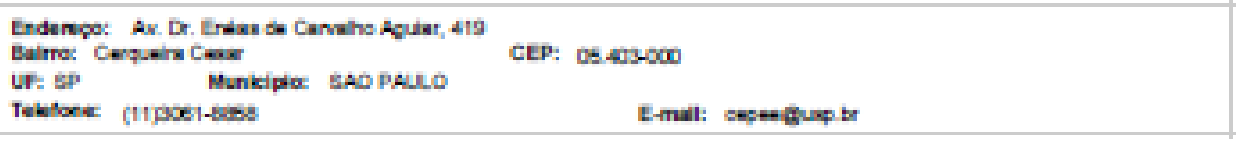




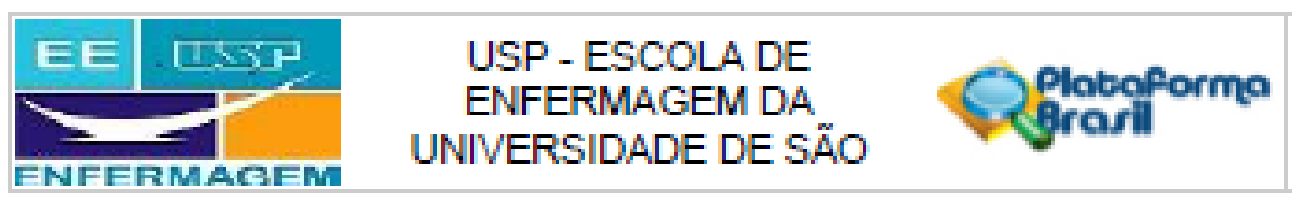

Cortinuaghs do Pavear 2.400 mes

Inclusbo: ser malores de 18 anos, que salbam ler e eacrever e que obtenham uma pontusçato no Alcohol Use Disorders identification Teat - AUDIT (Instrumento utlizado para identificar uso de risco e nocivo de alcool na populaçb masculina) entre B e 14 . Oa criterioa de excluabo incluirlo eatar em tratamento ou frequentar algum grupo relacionado com o uso de alcool, ser portador de incapacidade cognittia que impeça a compreenabo dos termos da pesquisa, estar intoricado ou sob efeito de alguma subatancla palcostiva, nfo possuir teiefone ou endereço residencial fxo. A amostra final sera composta por 42 sujetos (21 no grupo experimental e 21 no controle). Os instrumentos utlizados serdo AUDrT, alingle question, regus de prontidí para mudança (tecnica visual analogica com opçblo de 0 a 10 , elaborada com o objetivo de Identificar os estados de prontidSo para mudança) e entrevlata semiestruturada (sera realizada uma entreviata com os homena que tenham partcipado do estudo plloto com a seguinte pergunta norteadora: como fol a sua expentencla de participar no grupo de intervençblo breve grupal?), alem de um questionarioa sobre dadoa sociodemografcos doa participantea. Para o grupo experimental, serb aplicads a tecnica oEIRT, utilzando como foco a intervençlo breve grupal, desenvolvids em uma unica sessblo. Para o controle, serd oferecido o aconsel hamento simples durante um encontro ùnico de no maximo 5 minutos, que acontecers de forms indlwidus. O seguimento doa grupos (Intervençblo e controle) sera felto por tres avallaçbes posteriores ( 30 dlas, 60 dlas e 90 dlas) via teiefone. Durante as llgaçbes o avallador aplicart o Instrumento AUDIT e a single question, para verificar se houve diferenças no escore entre os grupos controle e experimental.

Objattvo da Pocquica:

Objetivo gera: Avallar o impacto da Intervençbio breve grupal na mudança do padrfo de uso em homena com uso de raco e nochvo de ticool na atençdo primaria a saúde. Objetvos eapecificos: Avallar o impacto da intervençlo breve grupa nos easaglos de prontidalo para mudança em homens com uso de riaco e noclvo de alcool na atençblo basica a saude; deacrever as experiencisa de mudança doa homens que participaram da lag realzada na abençbio primaria a saude; e descrever o perfl sociodemogrtfico dos homens que fazem uso de risco e nocivo no ambitb da stençlo basica s salde.

\section{Avallsyso doc Riceoc o Benefloloc:}

Ê possivel que o participante sinta algum desconforto do tipo emocional, decorrente da evocaçás de sentimentos, emoçbes e lembranças durante o atendimento. Caso lszo ocoma, os pesoulsadores estarbio a

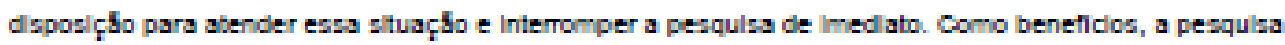

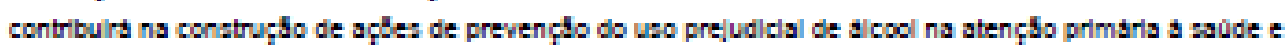
visars disponbllzzr uma intervençalo de facl

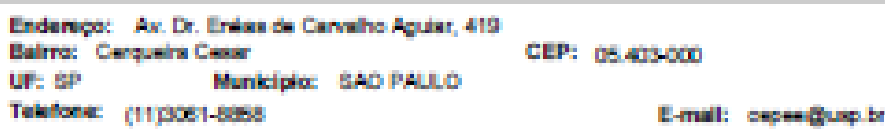




\section{Anexo 3}

\section{Aprovação Comitê de Ética em Pesquisa da Secretaria Municipal da Saúde de São Paulo}

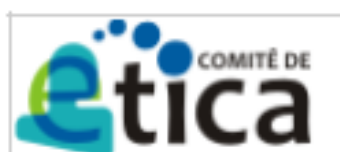

EM PESQUISA - SMS

\section{SECRETARIA MUNICIPAL DA}

SAÚDE DE SÃO PAULO SMS/SP

\section{PARECER CONSUBSTANCIADO DO CEP}

Elaborado pela Instituição Coparticipante

\section{DADOS DO PROJETO DE PESQUISA}

Título da Pesquisa: Intervenção breve grupal para redução do padrão de uso de álcool em homens: ensaio clínico randomizado

Pesquisador: DIVANE DE VARGAS

Área Temática:

Versão: 3

CAAE: 80385817.7 .3001 .0086

Instituição Proponente:Secretaria Municipal da Saúde de São Paulo - SMS/SP

Patrocinador Principal: Financiamento Próprio

\section{DADOS DO PARECER}

Número do Parecer: 2.565 .764

Apresentaçäo do Projeto:

A proposta é de estudo com foco breve grupal, com observância na mudança do padrão de homens com uso de risco e nocivo de álcool no âmbito da atenção primária à saúde.

A amostra é composta por 42 participantes, em UBS da CRS Centro.O estudo será composto por homens usuários de álcool que frequentam a unidade de atenção primária à saúde, que preencham os seguintes critérios de inclusão: ser maiores de 18 anos, que saibam ler e escrever e que obtenham uma pontuação no AUDIT entre 8 e 14 .

Critérios de exclusão: Estar em tratamento ou frequentar algum grupo relacionado com o uso de álcool, ser portador de incapacidade cognitiva que impeça a compreensão dos termos da pesquisa, estar intoxicado ou sob efeito de alguma substância psicoativa, não possuir telefone ou endereço residencial fixo.

Serão utilizados os seguintes instrumentos para coleta de dados:

O instrumento AUDIT (Alcohol Use Disorders Identification Test), single question que é uma pergunta ideal para identificação rápida do uso nocivo de álcool(validada no Br). Régua de prontidão para mudança técnica visual-análogica com opção de 0 a 10 , elaborada com o objetivo de identificar os estados de prontidão para mudança, entrevista semiestruturada e questionário de dados sociodemográficos. 


\section{SECRETARIA MUNICIPAL DA SAÚDE DE SÃO PAULO - SMS/SP}

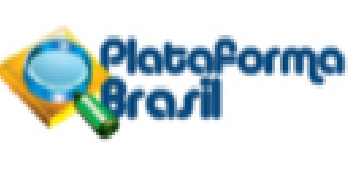

Continuaçdo do Parecer. 2565.764

deverá ser enviada à instância que autorizou a realização do estudo, via correio ou entregue pessoalmente, logo que o mesmo estiver concluído.

Este parecer foi elaborado baseado nos documentos abaixo relacionados:

\begin{tabular}{|c|c|c|c|c|}
\hline Tipo Documento & Arquivo & Postagem & Autor & Situação \\
\hline $\begin{array}{l}\text { Informaçöes Básicas } \\
\text { do Projeto }\end{array}$ & $\begin{array}{l}\text { PB_INFORMAÇŌES_BÁSICAS_DO_P } \\
\text { ROJETO 1074456.pdf }\end{array}$ & $\begin{array}{c}22 / 03 / 2018 \\
15: 39: 53 \\
\end{array}$ & & Aceito \\
\hline Outros & TCLE_corrigido.pdf & $\begin{array}{c}22 / 03 / 2018 \\
15: 38: 55 \\
\end{array}$ & \begin{tabular}{|l} 
DIVANE DE \\
VARGAS \\
\end{tabular} & Aceito \\
\hline $\begin{array}{l}\text { TCLE / Termos de } \\
\text { Assentimento / } \\
\text { Justificativa de } \\
\text { Ausência }\end{array}$ & TCLE.docX & $\begin{array}{c}08 / 01 / 2018 \\
12: 29: 57\end{array}$ & $\begin{array}{l}\text { DIVANE DE } \\
\text { VARGAS }\end{array}$ & Aceito \\
\hline $\begin{array}{l}\text { Projeto Detalhado / } \\
\text { Brochura } \\
\text { Investigador }\end{array}$ & projeto.docx & $\begin{array}{c}08 / 01 / 2018 \\
12: 29: 16\end{array}$ & $\begin{array}{l}\text { DIVANE DE } \\
\text { VARGAS }\end{array}$ & Aceito \\
\hline Outros & UBS.pdf & $\begin{array}{c}27 / 11 / 2017 \\
12: 40: 19 \\
\end{array}$ & \begin{tabular}{|l} 
DIVANE DE \\
VARGAS \\
\end{tabular} & Aceito \\
\hline Outros & COMITE_SMS.pdf & $\begin{array}{c}27 / 11 / 2017 \\
12: 39: 05\end{array}$ & $\begin{array}{l}\text { DIVANE DE } \\
\text { VARGAS }\end{array}$ & Aceito \\
\hline
\end{tabular}

Situaçäo do Parecer:

Aprovado

Necessita Apreciação da CONEP:

Năo

SAO PAULO, 27 de Março de 2018

Assinado por:

SIMONE MONGELLI DE FANTINI

(Coordenador) 


\section{Anexo 4}

Folheto educativo - Programa de Ações Integradas para Prevenção e Atenção a Álcool e Drogas - PAI PAD

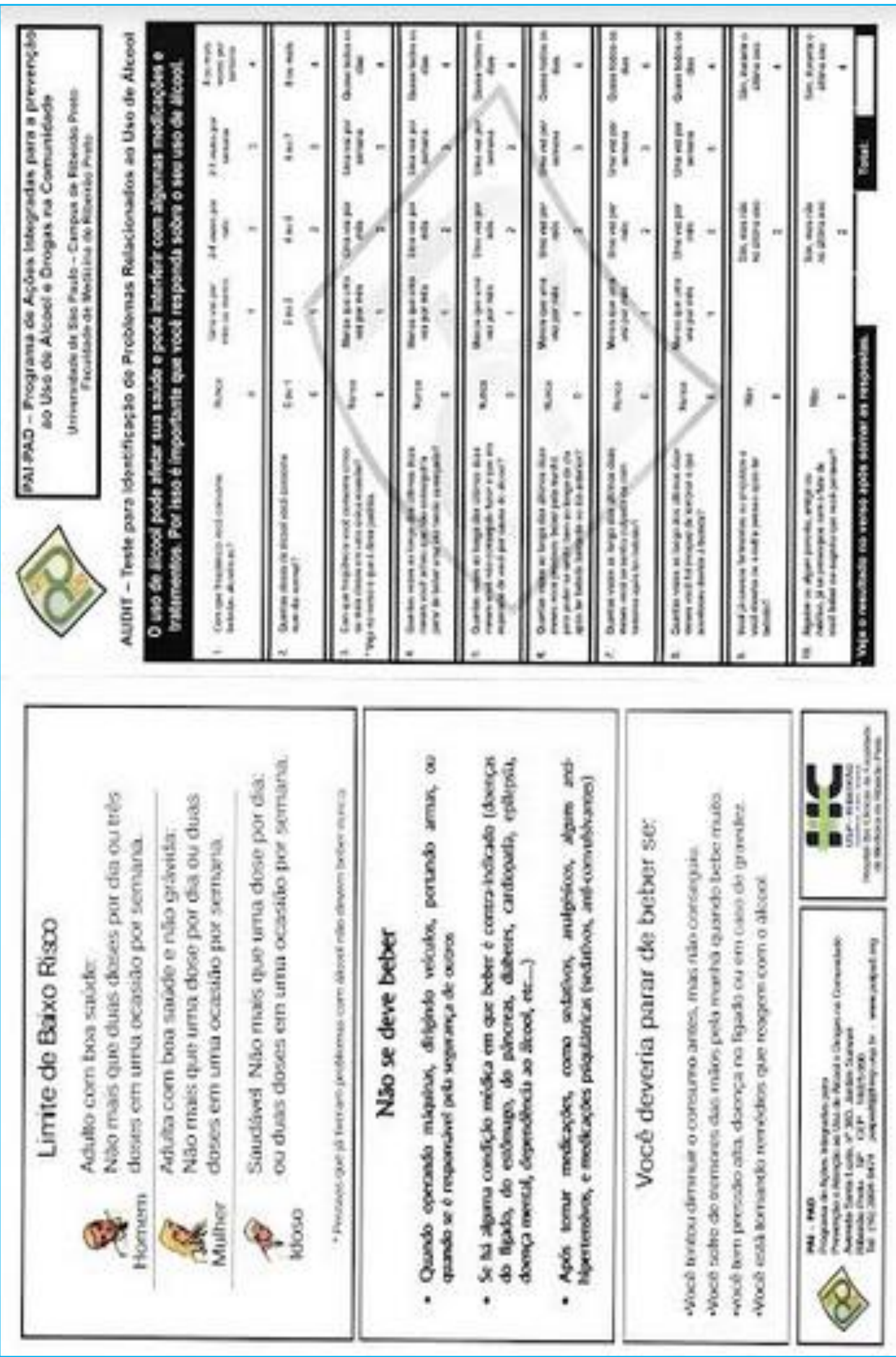



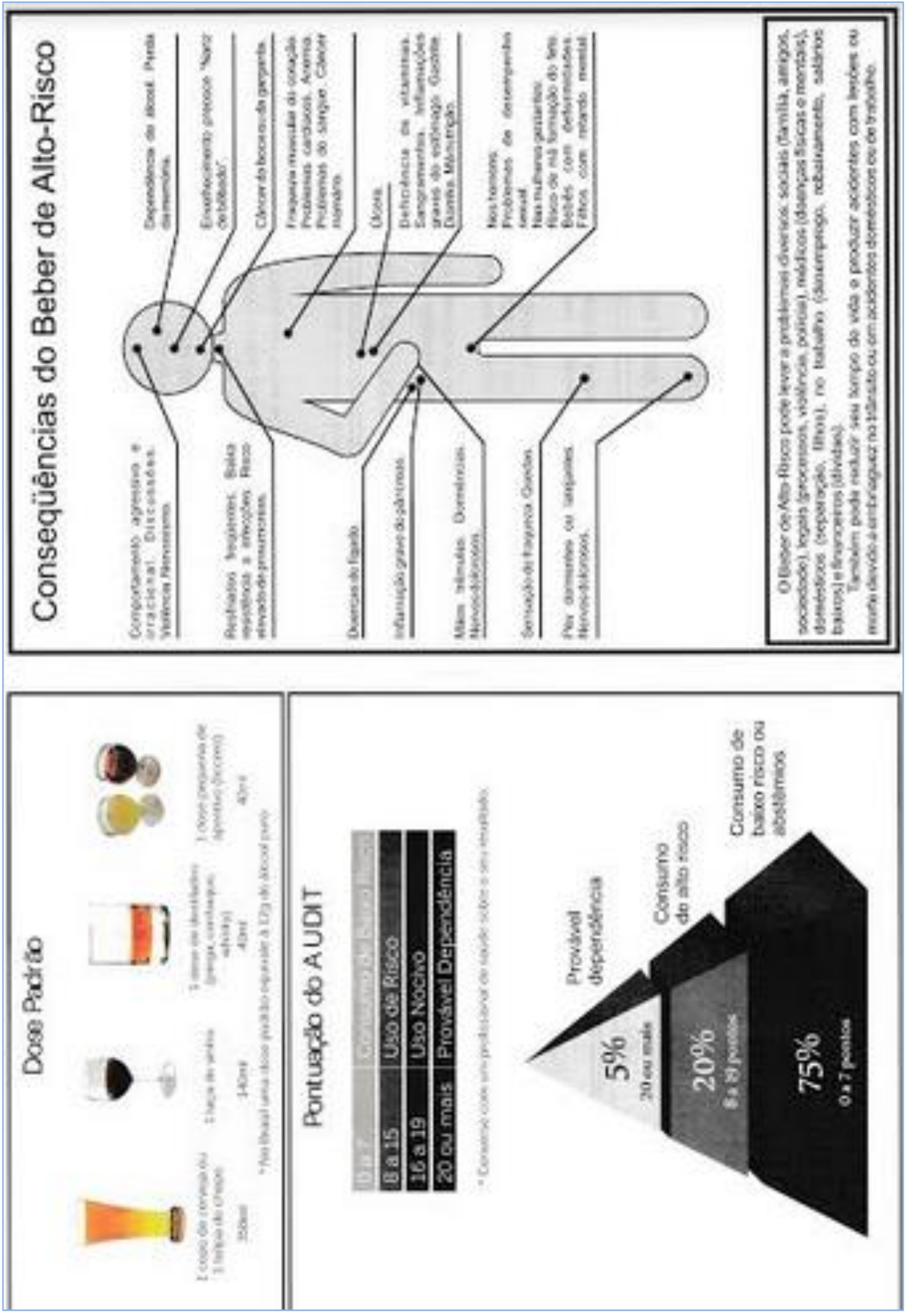


\section{Anexo 5}

\section{Atividade Balança Decisória}

Apontar os prós e os contras do uso de bebida alcoólica

Pró (coisas boas)

Contra (coisas ruins)

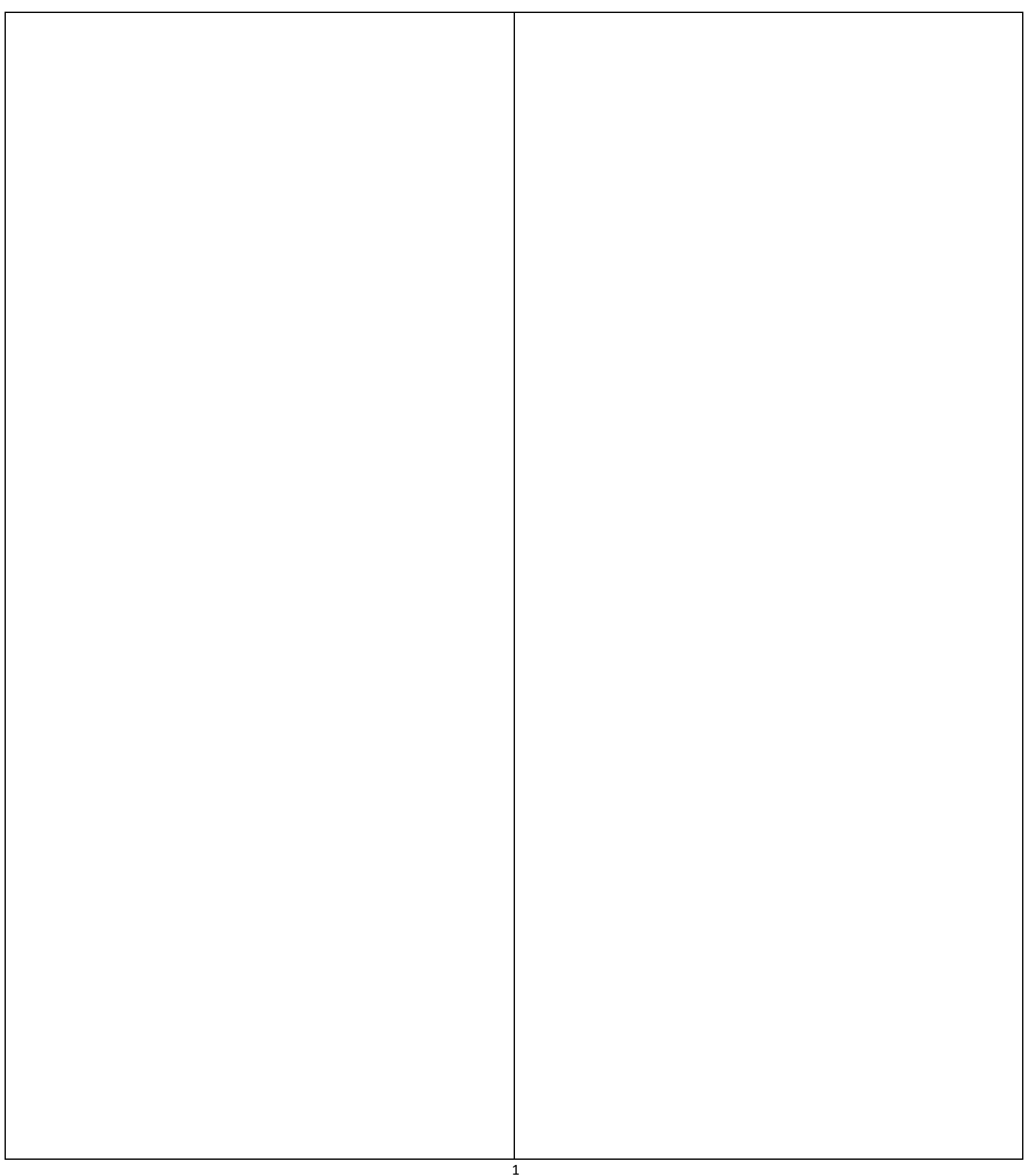

${ }^{1}$ Sobell M, Sobell L. Terapia de Grupo para transtornos por abuso de substâncias: abordagem cognitivocomportamental motivacional. Porto alegre, 2013. Pág. 91. 